\title{
BAN THE BOX, CRIMINAL RECORDS, AND STATISTICAL DISCRIMINATION: A FIELD EXPERIMENT*
}

\author{
Amanda Agan and Sonja Starr ${ }^{1}$
}

August 24, 2016

\begin{abstract}
"Ban-the-Box" (BTB) policies restrict employers from asking about applicants' criminal histories on job applications and are often presented as a means of reducing unemployment among black men, who disproportionately have criminal records. However, withholding information about criminal records could risk encouraging statistical discrimination: employers may make assumptions about criminality based on the applicant's race (or other observable characteristics). To investigate BTB's effects, we sent approximately 15,000 fictitious online job applications to employers in New Jersey and New York City both before and after the adoption of BTB policies. These applications varied the race and felony conviction status of the applicants. We confirm that criminal records are a major barrier to employment: employers that ask about criminal records were $63 \%$ more likely to call back an applicant if he has no record. However, our results support the concern that BTB policies encourage statistical discrimination on the basis of race: we find that the race gap in callbacks grows dramatically at the BTB-affected companies after the policy goes into effect. Before BTB, white applicants to employers with the box received $7 \%$ more callbacks than similar black applicants, but BTB increases this gap to $45 \%$.
\end{abstract}

JEL Codes: J15, J78, K31, K42

\footnotetext{
* The authors gratefully acknowledge generous funding from the Princeton University Industrial Relations Section, the University of Michigan Empirical Legal Studies Center, and the University of Michigan Office of Research, without which this study could not have taken place. We thank Will Dobbie, Henry Farber, Alan Krueger, Steven Levitt, Alex Mas, Emily Owens, Alex Tabarrok, David Weisbach, Crystal Yang and seminar participants at Princeton University, Rutgers University, the University of Chicago, the University of Michigan, UCLA, the University of Pennsylvania, the University of Toronto, the University of Virginia, the University of Notre Dame, the Society of Labor Economists Annual Meeting, the IRP Summer Workshop, the American Law and Economics Association Annual Meeting, and the NBER Summer Institute Labor Studies/Crime Session for helpful comments. Finally, we thank every member of our large team of research assistants for their hard work and care, especially head RAs Louisa Eberle, Reid Murdoch, Emma Ward, and Drew Pappas, and our ArcGIS experts Linfeng Li and Grady Bridges.

${ }^{1}$ Agan: Rutgers University aagan@econ.rutgers.edu; Starr: University of Michigan sbstarr@umich.edu.
} 


\section{Introduction}

In an effort to reduce barriers to employment for people with criminal records, more than 100 jurisdictions and 23 states have passed "Ban-the-Box" (BTB) policies (Rodriguez and Avery 2016). The "box" referred to in "Ban the Box" (and hereinafter in this paper) is the question on a job application form asking whether the applicant has been convicted of a crime - which is often accompanied by yes and no checkboxes. Although the details vary, BTB policies all prohibit employers from asking such questions on the initial job application or in job interviews; employers may still conduct criminal background checks, but only at or near the end of the employment process. $^{2}$ Most BTB policies apply to public employers only, but seven states (including New Jersey) and a number of cities (including New York City) have now also extended these restrictions to private employers.

BTB laws seek to increase employment opportunities for people with criminal records. Their basic premise, which finds support in prior research, is that having a criminal record, especially a felony conviction, is a substantial barrier to employment (Pager 2003; Holzer et al. 2006; Holzer 2007). Although BTB laws only delay (rather than permanently bar) employer access to criminal records, the theory is that after meeting applicants in person, employers are less likely to treat records as being categorically disqualifying: "Rejection is harder once a personal relationship has been formed" (Love 2011). Thus, BTB's objective is to enable candidates with records to get their foot in the door.

BTB is often further presented as an important tool for reducing racial disparity in employment, and especially for improving access to employment for black men (Pinard 2014, Southern Coalition for Social Justice 2013, Clarke 2012, and Community Catalyst 2013), who have in recent years faced unemployment rates approximately double the national average (Bureau of Labor Statistics 2015). ${ }^{3}$ The reasoning behind this theory is straightforward: the employment

\footnotetext{
${ }^{2}$ In New Jersey and New York City, the two jurisdictions on which this study focuses, employers may conduct background checks anytime after first interview (New Jersey) or after a conditional job offer is made (New York). Some BTB laws also substantively restrict the role that criminal records can play in employers' ultimate decisions, but New Jersey's and New York's do not. New Jersey's law affects only the "initial employment application process" (N.J. P.L. 2014, Ch. 32). New York requires employers to consider whether a conviction is job-relevant, but this is a longstanding restriction that was unchanged by BTB. N.Y. Correction Law Sec. 752. All U.S. employers have also long been subject to similar restrictions (requiring nuanced assessments of criminal records) at the federal level, pursuant to the Equal Employment Opportunity Commission's interpretation of the Civil Rights Act of 1964 (EEOC 2012).

${ }^{3}$ See for example Minnesota Department of Human Rights (2015): "The Ban the Box law can mitigate disparate impact based on race and national origin in the job applicant pool, and is one tool to help reduce these inequalities." New York
} 
hurdles associated with criminal records should disproportionately affect black men, because black men are more likely to have records (Brame et al. 2014, Shannon et al. 2011). ${ }^{4,5}$ Thus, if BTB effectively opens doors for people with records, it should help to mitigate this source of racial disparity in employment.

There is, however, a plausible counterargument to the view that BTB will improve black male employment prospects. In the absence of individual information about which applicants have criminal convictions, employers might statistically discriminate against applicants with characteristics correlated with criminal records, such as race (Phelps 1972, Arrow 1973, Stoll 2009). In this scenario, applicants with no criminal records who belong to groups with higher (perceived) conviction rates, such as young black males, would be adversely affected by BTB policies. Meanwhile, white applicants with records might disproportionately benefit, due to employers making group-based assumptions in their favor.

We investigate the effects of BTB laws via a field experiment. We submitted nearly 15,000 fictitious online job applications to entry-level positions before and after BTB laws went into effect in New Jersey (March 1, 2015) and New York City (October 27, 2015). We sent these applications in pairs matched on race (black and white), which was our primary variable of interest. We also randomly varied whether our applicants had a felony conviction as well as two other characteristics that could also potentially signal criminal history to employers: whether the applicant has a GED, and whether the applicant has a one-year employment gap. ${ }^{6}$

Our study explores several key questions. First, we investigate whether employer callback rates vary by race and by felony conviction status, and whether there is an interaction between these effects. Second, we estimate how taking criminal history off the job application pursuant to BTB changes the racial gap in callback rates. To answer this question, we exploit the fact that some employers, even absent BTB, choose not to ask about criminal convictions on employment

City's public-sector Ban the Box law was passed as part of the Young Men's Initiative, an initiative designed to address disparities faced by young Black and Latino men (City of New York 2016). Civil rights organizations are also major supporters of Ban the Box movements (NAACP 2014, Color of Change 2015).

${ }^{4}$ Brame et al. (2014) find that by age $23,49 \%$ of black men have experienced an arrest versus $38 \%$ of white men; Shannon et al. (2011) estimate that $25 \%$ of the U.S. black population has a felony conviction, compared with only $6 \%$ of the non-black population.

${ }^{5}$ This disparate impact is why EEOC interprets race discrimination law to constrain employers' treatment of criminal records (EEOC 2012).

${ }^{6}$ We use "criminal record" and "felony conviction" interchangeably here; our experimental design varies whether applicants have a felony conviction. Employers that ask about records on initial job applications overwhelmingly limit their questions to convictions (not arrests), and most limit them to felony convictions specifically. 
applications. We thus estimate BTB's effects on racial discrimination at affected employers after differencing out changes over the same time period among similar employers whose applications were unaffected by BTB. We also estimate the effects of having a GED and of a one-year employment gap.

Our experiment supports several key findings. When employers ask about criminal convictions, the effect of having a felony conviction is significant and large: applicants without a felony conviction are 63\% (5.2 percentage points over a baseline of $8.2 \%$ ) more likely to be called back than those with a conviction, averaged across races. In contrast to prior research (Pager 2003; Pager, Western, and Bonikowski 2009), we find no significant interaction between the effects of race and felony convictions. And although one might have expected that a GED (versus a high school diploma) or a 1-year gap in employment might have been disfavored or used by employers as a proxy for a criminal record, neither characteristic significantly affects callback rates.

We find that BTB substantially increases racial disparities in employer callbacks. Specifically, after differencing out changes over the same period at unaffected companies, we find that BTB expands the black-white gap by about 4 percentage points. This is a large expansion given that the overall callback rate for the sample was just under $12 \%$. Indeed, in our main specification, the black-white gap at affected businesses increased by a factor of about six: before BTB, white applicants received 7\% more callbacks than similar black applicants, but after BTB this gap grew to $45 \%$.

This increase in racial inequality in callback rates appears to come from a combination of losses to black applicants and gains to white applicants. In particular, black applicants without criminal records see a substantial drop in callback rates after BTB, which their white counterparts do not see. Meanwhile, white applicants with criminal records see a substantial increase in callbacks, which their black counterparts do not see. This pattern suggests that when employers lack individualized information about criminal history, they tend to statistically generalize that black applicants are likely to have records and white applicants are likely not to have them. As we explain in the Discussion, there is good reason to believe that these generalizations are exaggerated relative to real-world racial differences in felony conviction rates.

This study makes several distinct contributions to the literature. First, this is the first experimental study of BTB's statistical discrimination effects, and we hope it will inform ongoing legislative debates about BTB throughout the country. Second, removing information about 
criminal history on job applications allows us to use field-experimental methods to contribute to the literature on statistical discrimination in employment, which has not generally used such methods. ${ }^{7}$ Although our study is not a pure experiment (a key variable, whether the application asks about records, is not manipulated), our ability to perfectly observe and randomize all of our fictional applicants' characteristics allows us to avoid many of the most likely threats to causal inference that affect purely observational research, and leaves us better equipped than are purely observational researchers to tease out the mechanisms underlying the effects we observe.

Finally, we make a methodological contribution to the literature on auditing, which has for decades been a central tool for empirical research on discrimination in employment, housing, lending, and other areas. To our knowledge, this is the first study to use auditing to assess the effects of a policy, rather than to obtain a static picture of discrimination patterns. Because researchers cannot randomize the application of the policy itself, using auditing to assess policies requires combining the field-experimental approach with additional methods of causal inferencein this case, difference-in-differences analysis. We believe that combining auditing with quasiexperimental analysis of policy changes enriches the study of discrimination.

\section{Prior Research on Statistical Discrimination}

Economists have frequently suggested that when specific information about individuals is unavailable or costly, decision-makers are more likely to rely on statistical generalizations about groups (Phelps 1972; Arrow 1973; Aigner and Cain 1977; Fang and Moro 2011). In our context, this theory implies that if employers do not know which applicants have criminal records, they may make race-based assumptions about the probability of a criminal history, triggering discriminatory treatment (Finlay 2009; Freeman 2008; Holzer et al. 2006). Although BTB does not permanently bar employers from obtaining record information, employers may want to avoid the costs associated with interviewing and making tentative offers to candidates that they fear will ultimately be disqualified.

Thus, black men without criminal records could be hurt by BTB if employers assume that they are likely to have a record. If so, it would subvert the policy objective of expanding their access to employment. Moreover, such discrimination would plainly be unlawful: Title VII of the Civil Rights Act of 1964 prohibits hiring discrimination based on race as well as gender, and does

\footnotetext{
${ }^{7}$ See List (2004) for an experimental approach to statistical discrimination in another context, sports card trading.
} 
not permit otherwise-illegal treatment to be based on statistical generalizations about groups (even if empirically supported). ${ }^{8}$ This rule reflects a policy judgment disfavoring racial generalizations and favoring expansion of workplace opportunities for historically excluded groups. But these restrictions are famously difficult to enforce, and the fact that statistical discrimination would be an unlawful response to BTB does not mean it is impossible, or even unlikely.

Three recent working papers study the impact of BTB policies on statistical discrimination in employment with observational data from the CPS and/or ACS and come to mixed conclusions (Starr 2015, Doleac and Hansen 2016, Shoag and Veuger 2016). Starr's preliminary results using the CPS show a substantial increase in racial disparity in rates of being employed by local governments after public BTB policies go into effect, but her analysis of the ACS shows no significant change. Doleac and Hansen (2016) find similarly that in the CPS there is a decrease in employment for black and Hispanic men after BTB goes into effect. Shoag and Veuger (2016), on other hand, use ACS data and show that employment of black men increased after BTB. It is still early to study private-sector BTB policies in these surveys (most of which are very recent), so these papers focus on public-sector policies. Both the ACS and CPS datasets have some substantial limitations that might explain the differences in results (Starr 2015). ${ }^{9}$

Outside the BTB context, several observational studies have considered the relationship between employer access to criminal records and race gaps in employment. Bushway (2004) finds that Internet-based criminal records databases are associated with reduced race gaps in employment; in contrast, Finlay (2014) finds that while young black men without records benefit, these databases' net employment effect on young black men appears to be negative. Holzer et al. (2006) and Stoll (2009) find that surveyed employers who report that they use criminal records checks are more likely to hire African-Americans. Other studies find that employers also appear to statistically discriminate by race in the absence of drug testing and credit checks (Wozniak 2015, Clifford and Shoag 2016, and Bartik and Nelson 2016). Autor and Scarborough (2008) find that a retail chain's

\footnotetext{
${ }^{8}$ For example, in City of Los Angeles Dep't of Water and Power v. Manhart, 435 U.S. 702 (1978), the Supreme Court held that an employer could not rely, in designing pension benefits, on the actuarial prediction that women live longer. ${ }^{9}$ As Starr (2015) explains, these datasets do not distinguish between county and city employment, code geography in regional units that often only roughly track the geographic scope of local BTB policies and that (in the case of the ACS) have changed over time, provide no information (in the case of the CPS) about the location of employers as opposed to respondents, and (in the case of the ACS) annualize the data, losing temporal precision. These limitations mean that whether and how long BTB is in effect and whether a respondent's job is among those covered by it can only be imprecisely measured. Moreover, because these surveys do not include questions about criminal records, they cannot be used to distinguish BTB's effects on applicants with and without records.
} 
adoption of a pre-employment personality test did not hurt black employment success even though black candidates had lower scores; they interpret this as evidence that employers were statistically discriminating before they used the test.

\section{Experimental Design}

Our field-experimental approach, commonly known as "auditing," involves randomly varying characteristics of interest about a (fictitious) person with whom a subject interacts, while holding other characteristics constant. Similar experiments have been used to test employment discrimination on the basis of race, gender, length of unemployment spell, age, commute time, and type of postsecondary education (Neumark 1996; Riach and Rich 2002; Bertrand and Mullainathan 2004; Lahey 2008; Oreopoulos 2011; Neumark 2012; Kroft et al. 2013; Deming et al. 2014; Farber et al. 2015; Neumark et al. 2015; and Phillips 2016), as well as the effects of criminal records and their interaction with race (Pager 2003, Pager et al. 2009, and Uggen et al. 2014, Decker et al. 2014). Auditing has previously only been used to obtain a one-time snapshot of discrimination in a particular decision process; we show here that a repeated audit design can also be used to assess the effects of a policy.

Specifically, we submitted online job applications on behalf of fictitious job applicants to low-skill, entry-level job openings both before and after BTB went into effect in New Jersey and New York City. New Jersey's version of BTB, the "Opportunity to Compete Act", was passed on August 11, 2014 and became effective March 1, 2015. We submitted applications in New Jersey in the pre-BTB period between January 31 and February 28, 2015 and in the post-BTB period between May 4 and June 12, 2015. New York City's BTB law went into effect on October 27, 2015. We submitted applications in New York City between June 10 and August 30, 2015 (the pre-BTB period) and between November 30, 2015 and March 31, 2016 (the post-BTB period).

\subsection{Choosing Employers and Job Postings}

Our subjects were exclusively private, for-profit employers. We principally targeted chain businesses because such businesses are likely to have online job applications and to be subject to the New Jersey BTB policy, which exempts employers with fewer than 15 employees. We relied on two main sources for locating job openings. First, we searched snagajob.com and indeed.com, two large online job boards; snagajob.com focuses specifically on hourly employment. Second, with certain exceptions, we also directly searched the employment websites of chain businesses meeting 
certain size criteria. ${ }^{10}$ We searched specifically for jobs suitable for candidates with limited work experience, no post-secondary education, and no specialized skills. Such jobs are predominantly non-supervisory team-member jobs at fast food and other restaurants, grocery and convenience stores, and other retail establishments. We focus on these sectors because they almost universally use job applications (particularly online applications) rather than resumes as an initial screen of job applicants; employers that do not use applications do not have a "box" that can be banned. In addition, these sorts of jobs are likely to attract applicants with criminal records, who disproportionately tend to have relatively little work experience or post-secondary education.

\subsection{Applicant Profiles}

Our fictitious applicants are all male and approximately 21 to 22 years old. ${ }^{11}$ The applications were submitted with the assistance of a large team of University of Michigan student research assistants. They based the applications on profiles that we created using the Resume Randomizer program created by Lahey and Beasley (2009). Each applicant profile included a name, a phone number, an address, an employment history consisting of two prior jobs, a unique email address, two references with phone numbers, information on high school diploma or GED receipt, a felony conviction status and information about the criminal charge, a formatted resume, and answers to many other routine application questions concerning job requirements, availability, and pay sought (minimum wage). ${ }^{12}$

The profiles were created in pairs, each consisting of one black and one white applicant. These pairs were assigned to the same store in the same time period. Our applicants were all similar on all but our randomly assigned treatment dimensions. In addition to race, those dimensions are:

\section{(1) Has felony criminal conviction or not}

\footnotetext{
${ }^{10}$ In New Jersey, we applied to businesses with at least 30 locations and 300 employees in the state. In New York, we applied to these same chains, plus other chains with at least 20 locations in the city. We excluded employers that did not use online job applications, although the vast majority of chains meeting those size criteria (or advertising on Snagajob or Indeed) do use them. We excluded a few chains due to extremely arduous online application processes, and a few that targeted an overwhelmingly female clientele. Finally, some employers required full SSNs on job applications. For ethical reasons, we avoided using potentially real SSNs, instead using invalid SSNs beginning with 9xx or 666. Some employers had systems that automatically detected these invalid SSNs, and we excluded those businesses. If setting up such a system could be correlated with special interest in criminal records, then excluding this pool could reduce our estimates of the effects of a criminal record. However, among employers we did apply to, there was no correlation between whether employers asked for an SSN at all and whether they asked about criminal records.

${ }^{11}$ Employers rarely ask about age due to age discrimination laws, but could infer it from the length of work history.

${ }^{12}$ It was not possible for the profiles to anticipate every question asked, especially as many applications require an extensive online personality or skills assessments. For this reason, we relied on the RAs' judgment, but provided detailed training about what employers are generally looking for.
} 
a. (Conditional on conviction): convicted of property crime or drug crime

(2) Has 1-year employment gap versus a 0- to 2-month gap (referred to as "no gap" below) between the two past jobs

\section{(3) GED or High School Diploma}

These characteristics were randomized with equal (50\%) probability. In addition to race, we chose to vary the employment gap and high school diploma status because they are also characteristics that hiring managers might perceive as correlated with criminal history. ${ }^{13}$ Race is indicated via the name of the applicant, as discussed further in Section 3.3 below. The crimes our applicants were convicted of were nonviolent, relatively minor felonies - either property crimes (e.g., shoplifting, receiving stolen property, theft) or drug crimes (e.g., controlled substances possession).

We chose 40 geographically distributed cities/towns in New Jersey and 44 neighborhoods throughout New York City's boroughs to serve as "centers" where the applicants' addresses would be located; each center then served as a base for application to nearby employers. ${ }^{14}$ All applicant addresses were in racially diverse, lower- to middle-class neighborhoods. Other job applicant characteristics such as work history, address within center, and high school name or GED program were designed to have similar connotations, although they were randomly varied among a set of similar options (e.g., different high schools with similar demographic and academic profiles) and forced to differ within pairs so as to disguise the similarity of the applications. Each applicant received a unique email account with the address format randomly varied. Phone numbers were assigned at the center/race/crime level and thus shared by multiple applicants, but in a way that almost entirely avoided using the same number more than once within any chain. For more details on profile contents and applicant characteristics, see Appendix A1.

\footnotetext{
${ }^{13}$ As of 2005, 13.6\% of GEDs were issued in state and federal Prisons (Heckman and LaFontaine 2010). The relationship between GED, race, and criminal records is further addressed in the Discussion. The one-year employment gap is meant to signal potential time spent incarcerated or dealing with the criminal justice process. The absence of a gap does not necessarily imply absence of a conviction, however, because offenders are often not incarcerated. Among all individuals charged with felonies in state courts, $62 \%$ are not detained before trial; $27 \%$ of those convicted receive no incarceration, and of those incarcerated $48 \%$ receive sentences of 1-3 months (Reaves 2013). Incarceration rates are presumably lower yet among first-time offenders with relatively minor felonies, like our fictional felon applicants.

${ }^{14}$ In New Jersey, we assigned each municipality in the state to its nearest center, minimizing distance. In New York City, because distances are much smaller generally, we prioritized distributing the locations of each chain across centers, and minimized distance within equal-distribution constraints.
} 


\subsection{Indicating Applicant Race}

Race is the central characteristic of interest in our study, and we signal race by the name of the applicant (Bertrand and Mullainathan 2004; Oreopoulous 2011). To identify racially distinctive names, we used birth certificate data for babies born between 1989 and 1997 from the New Jersey Department of Health (NJDOH), which encompasses the cohort that would include our applicants (Center for Health Statistics n.d.). We then chose a set of first and last names that were racially distinctive (meeting threshold requirements for the percentages of babies given that name who were black or non-Hispanic white) and common (meeting threshold requirements for the total number of babies born with that name and race). ${ }^{15}$ Each applicant was then assigned a random first name and random last name from the appropriate list. We expect that the combination of racially distinctive first and last names will produce a very strong racial signal: according to the birth certificate data, $97 \%$ of persons with first and last names on our "black" list are black, and $92 \%$ of persons with first and last names on our "white" list are white. A list of the names we used is provided in Appendix A2.

One concern about this strategy is that racially distinctive names could also signal socioeconomic status, which employers may also believe to be correlated with productivity (Fryer and Levitt 2004). We note first that our applications provided a great deal of concrete SES-related information to employers, including complete work histories, education, current neighborhood, high school location, and wage sought. Employers thus hardly need to rely on names to draw SES inferences, and it thus seems unlikely that they would do so (whereas the other information on the applications was designed to neutralize race signals, leaving the name as the only signal of race).

Nevertheless, to mitigate this concern, we limited our white name choices to those falling below the socioeconomic median for whites (as measured by maternal education recorded on the birth certificate, the best available indicator), reducing the implied-SES gap between our white and

\footnotetext{
${ }^{15}$ Because blacks are a much smaller fraction of the population, these thresholds varied by race: the minimum percentages were $80 \%$ for white first names, $85 \%$ for white last names, and $70 \%$ for black first and last names, while the minimum frequencies were 450 for white first names, 150 for white last names, 150 for black first names, and 100 for black last names. We eliminated a few first names that either were not distinctively male or that had strong associations with a particular religion, so as to avoid confounding the effects of race with those of perceived gender or religion. A heavily overlapping name list would have been chosen had we classified names in the manner of Bertrand and Mullainathan (2004) or Fryer and Levitt (2004).
} 
black names. ${ }^{16}$ In addition, we chose common names, avoiding any perceived socioeconomic connotations that may be associated with unusual names or spellings. Although some SES gap remains, it is very similar to the overall SES gap between black and white citizens-that is, choosing distinctive names did not amplify the gap. ${ }^{17}$ Distinctively white or black names do not point to an individual being a high- or low-SES outlier within their race; in fact, such names are very common. In our birth certificate sample, $47 \%$ of black children have a racially distinct first name and 36\% have a racially distinct last name (as we define distinctiveness, see footnote 15), while $35 \%$ of white children have a racially distinct first name and $65 \%$ have a racially distinct last name. Thus, to the extent employers make assumptions about SES based on racially distinctive names, these are assumptions that would affect a large fraction of real-world job applicants.

\subsection{The Job Application Process}

As described above, our RAs identified jobs and applied to them using randomly assigned profiles. With some time lag, a second application was submitted to each store, using the other member of the profile pair. Order within pairs was randomized, such that the black applicant applied first half the time. While submitting the job application, the RAs filled out a spreadsheet that indicated details about the employer, position applied to, and the questions asked on the application. Most applicant profiles (59\%) were sent to only one business. However, we sometimes used the same profile pairs to apply to multiple nearby locations of the same chain, as real-world applicants might do; our criteria for grouping the applications in this way differed between New Jersey and New York City, producing more grouping in New Jersey. ${ }^{18}$

The post-BTB application procedure was essentially the same, except that we began with the chains that we had already identified and applied to in the pre-period. The RAs were assigned to

\footnotetext{
${ }^{16}$ It was not possible to create lists of racially distinct names that are equivalent on SES indicia; virtually every distinctively white name averages higher than virtually every distinctively black name, due to socioeconomic stratification by race.

${ }^{17}$ According to the birth certificate data, persons with first and last names that were both on our "black" lists had an average maternal education level that was nearly identical to the overall black average; persons with first and last names that were both on our "white" lists had nearly the same average maternal education as the overall white average.

${ }^{18}$ In New Jersey, we were concerned that the same hiring managers might cover multiple locations of chains and might become suspicious upon noticing groups of similar applicants coming within a short time from the same nearby town. Accordingly, we used the same applicant profiles for all locations that were assigned to a given center, as though just one applicant was applying. In New York, our concerns were different: the centers are not towns and likely appear less distinctive to managers, and we had more available time before BTB's effective date, so we were able to space out the timing of our applications (generally by a month or more). Thus, in New York we chose to increase power by sending each application to only one location, except for the largest five chains (in which we sent each applications to up to two or three stores).
} 
submit applications to particular locations in an order that was designed to make the length of time between members of each pair roughly mirror what occurred in the pre-period. Stores thus received up to four applications total, one pair in each period.

It was sometimes not possible to send a complete set of four applications to an establishment. The primary reason for this was that the store was hiring in one period but not the other. In addition, a few RA assignments were not completed before BTB's effective date; this especially occurred in the New Jersey pre-period, our first wave of applications, which had to be completed relatively quickly. In New Jersey, we filled in these gaps in the post-period whenever possible, and identified some new opportunities on snagajob.com. In New York City, our preperiod wave represented a quite comprehensive search, so we limited the post-period wave to the same locations that we had sent at least one application to in the pre-period; there was some attrition due to unavailable jobs in the post-period. As a result, while the pre-and post-period samples are almost identical in size, the sample composition by chain, jurisdiction, and specific store is not identical across periods. We address these concerns below.

\subsection{Measuring Outcomes}

The main outcome of interest is whether an applicant receives a voicemail or email from an employer requesting that the applicant contact them or requesting an interview. We refer to this outcome as a callback (although it includes emails). For some alternative specifications, we focus on responses that specifically requested an interview. However, this outcome variable is subject to measurement error because employer messages often do not specifically mention an interview even if they are seeking to interview the applicant. Thus, our preferred specification uses the callback as the outcome. Phone calls and emails were tracked for eight weeks from the application date. In New Jersey, our pre-BTB data collection ended on April 25, 2015 (for the last applications sent); ${ }^{19}$ our post-BTB data collection ended on August 6, 2015. In New York City, our pre-BTB data collection ended on October 26, 2015, and our post-BTB data collection ended on May 26, $2016 .^{20}$

\footnotetext{
${ }^{19}$ Note that although this is considerably after BTB went into effect, all of the applications were submitted before it went into effect, which meant that the applications did contain the criminal records question (except for businesses that voluntarily omitted the question even prior to BTB). Because our outcome of interest is the employer response to the initial application (not subsequent stages of employer decision-making, such as ultimate hiring decisions), consideration of these applicants should therefore not be affected by BTB.

${ }^{20}$ Other than leaving a brief message saying the applicant was no longer available, we had no further communications with the businesses and, per IRB constraints, collected no information about the individuals we interacted with.
} 


\section{Summary Statistics and Main Effects of Applicant Characteristics on Employer Callbacks}

We submitted a total of 15,220 applications, of which 14,640 are included in our analysis sample. $^{21}$ This includes 6,401 applications in New Jersey and 8,239 in New York City. The applications were sent to 4,292 establishments ("stores") in 296 chains. We begin with summary statistics and then analyze the main effects of our randomly varied characteristics on employer callbacks. The summary statistics and results presented in the tables and figures below combine both jurisdictions; in Appendices A4 and A5, we replicate several of the tables and figures for New Jersey and New York separately.

\subsection{Summary Statistics}

Summary statistics are presented in Table 1a, by period and overall. As expected, approximately $50 \%$ of our applications had each of our randomized characteristics of interest. However, our other characteristic of interest - whether the application had the criminal-recordquestion "box" — could not be randomized. Among our pre-period applications, 36.6\% had the box, while in the post-period, 3.6\% still had it (noncompliers). This left approximately 33\% of the sample as "treated" observations: those that had the box before BTB, but not after.

Overall, $11.7 \%(1,715)$ of our applications received callbacks. ${ }^{22}$ This rate was slightly higher in the post-period (12.5\% vs. 10.9\%), and considerably lower in New York City than in New Jersey (9.4\% vs. 14.7\%; see Appendix Tables A4.1 and A5.1). Among the callbacks, about 55\% specifically mentioned an interview. The race gap in callback rates grew from 2.1 percentage points in the pre-period to 2.8 percentage points in the post-period, although these averages do not

\footnotetext{
${ }^{21}$ The remaining 580 observations (3.8\% of those we sent) were dropped for several reasons. First, when an entire chain was applied to only in the pre-period or only in the post-period, we had no way to code whether the application had the criminal record "box" in the other period, so the treatment variable could not be coded.

Second, some stores had inconsistencies within one or both rounds as to whether the box was present. The most common reason was early precompliance with BTB (which was announced several months before it went into effect), occurring before we sent the second application but after the first. Another reason was RA mistakes in interpreting the job application form-usually missing a disclaimer telling New Jersey or New York City applicants not to answer the criminal records question. In either event, when the two observations from the same store and round were in conflict, we discarded the observation that was an outlier from the overall chain norm. The effect was to drop RAmistake observations, and in the precompliance cases, to drop the later, non-box observation.

Third, we also dropped some businesses (about $1 \%$ of the sample) that appeared, mysteriously but presumably due to an administrative mistake, to add the box after BTB, and therefore could not be coded as 0 or 1 on the Treated variable. We add these back in in a robustness check below, with the coding of -1 .

${ }^{22}$ This rate is similar to other recent audit studies: Kroft et al. (2013) had a positive response rate of $11.6 \%$; Deming et al. (2014) had an $8.2 \%$ callback rate; Farber et al. (2015) a 10.4\% callback rate.
} 
differentiate treated and untreated observations, and mask large changes occurring at treated stores, as discussed below. Callback rates hardly differed by GED status or employment gap.

\subsection{Effects of Applicant Characteristics on Callback Rates}

We begin by assessing the underlying employment patterns that BTB is principally designed to address. How much of an effect does having a criminal record have on employer callback rates? How much does this vary by race? Table la did not show a breakdown of callback rates by criminal record status, because criminal record is unobserved by employers for $63 \%$ of our applications even in the pre-period. Instead, we show separate summary statistics in Table $1 \mathrm{~b}$ limited only to preBTB period observations where the application had the box. Among companies with the box before BTB goes into effect, callback rates are 60\% higher for applicants without criminal records $(5.1$ percentage points, over a base rate of $8.5 \%$ ). Applicants with drug convictions had similar callback rates to those with property crime convictions - perhaps surprisingly, as one might have expected employers to be particularly concerned about potential employee theft. When employers ask about records, we see essentially no race gap in callback rates: the white average is $11.1 \%$ and the black average is $10.9 \%$. For employers with the box in the pre-period, the callback rate advantage for applicants without records is slightly larger for white applicants (5.7 percentage points, or 69\% higher than the base rate of $8.3 \%$ ) than for black applicants (4.5 percentage points, or 52\% higher than the base rate of $8.6 \%$ ).

Figure 1 puts these numbers into perspective by comparing them to the callback rates for white and black applicants to employers without the box in the pre-period. Among these employers without the box, white applicants have a 3.1-percentage-point (or 33\%) callback rate advantage $(12.5 \%$ vs. $9.4 \% ; p<0.001)$. The overall callback rates at both groups of employers are essentially identical (11\%), but the separation between white and black applicants is seen only at the employers who do not ask about criminal records. This is suggestive evidence for the statistical discrimination theory, although other differences between these employers could potentially underlie these crosssectional differences; the triple-differences analysis below provides a stronger basis for causal inference. 
Table 2 provides multivariate regression estimates of the main effects of race, record, GED status, and employment gap on callback rates. ${ }^{23}$ These estimates closely parallel what we see in the summary statistics, which is not surprising given that all the applicant characteristics were distributed randomly. Column 1 implies that overall white applicants are on average about 2.4 percentage points (23\%) more likely to receive a callback from an employer. ${ }^{24}$ Column 2 adds chain fixed effects (with the smallest chains grouped by business category) and center fixed effects, which make little difference.

Columns 3 and 4 are limited to observations without and with the box, respectively. The criminal record variable is removed from the non-box Column 3 regression because no criminal record information was conveyed when there is no box. The advantage to white applicants appears only in the non-box sample, in which it is about three percentage points; there is no race gap at stores with the box. Column 4 also shows a statistically significant 5.2-percentage-point criminal record effect in the box sample. This effect size translates into a $63 \%$ higher callback rate for applicants without records, compared to the $8.2 \%$ baseline for applicants with records. Column 5 , which is also limited to observations with the box, shows that this effect is similar for property crimes and drug crimes.

Finally, Column 6 adds an interaction of the race and criminal record variables, within the box sample only. The negative criminal record effect is 1.5 percentage points larger for white applicants - among applicants without criminal records, whites have a slightly higher callback rate, but among applicants with criminal records, they have a slightly lower callback rate. This interaction is not statistically significant, but its sign is nonetheless interesting given that earlier, smaller auditing studies (Pager 2003; Pager et al. 2009) had found a suggestive interaction in the opposite direction.

In every specification and sample, having a one-year employment gap and obtaining a GED rather than a high school diploma have little effect on employer responses. Point estimates for both are close to zero, and the GED coefficient varies in sign across the specifications and samples.

\footnotetext{
${ }^{23}$ All the results shown in Table 2 are for both periods combined (unlike Table $1 \mathrm{~b}$ and Figure 1, which were for the preperiod only), but the regression results look similar if only the pre-period observations are used.

${ }^{24}$ Note that the estimated criminal record effect in these regressions (about 1.5 percentage points) substantially understates the magnitude of the real criminal record effect, because in four-fifths of the sample, criminal record was not actually conveyed to the employer.
} 
In Appendix A3 we show that the main effects of race and crime are robust to several alternative specification and samples. ${ }^{25}$ The main differences of note are geographic. There is a dramatic difference in the main race effect by jurisdiction: the "white" effect is far larger in New Jersey ( 4.5 percentage points versus 0.7 percentage points), and is statistically insignificant in New York City. While the overall callback rate is higher in New Jersey than in New York City (14.7\% compared to 9.4\%) this does not explain the difference: in New York City, white applicants receive $8 \%$ more callbacks than equivalent black applicants, while in New Jersey they receive about $37 \%$

more. ${ }^{26}$ The criminal record effect, in contrast, is larger in New York City than in New Jersey (in proportional terms). Conditional on having the box applicants without records receive $45 \%$ more callbacks than those with records in New Jersey; in New York City, applicants without records receive $78 \%$ more callbacks.

\section{Effects of Ban-the-Box on Racial Discrimination}

In this section we analyze the causal effect of banning the box on racial discrimination on employer callbacks. We start descriptively with Figure 2, which compares pre- and post-BTB call back rates among treated employers - that is, those that had the box in the pre-period but then removed it to comply with BTB. ${ }^{27}$ Just as with Figure 1 (the cross-sectional comparison), the temporal comparison suggests that when companies do not see applicants' criminal records, they are more likely to discriminate based on race. In this sample, in the pre-period, white applicants both with and without records have a slightly higher callback rate than equivalent black applicants do: for applicants without records, the white and black rates are $13.8 \%$ and $12.7 \%$ respectively, and for those with records, the white and black rates are $8.8 \%$ and $8.4 \%$, respectively. Averaging these subgroups together, the overall pre-period callback rates in this sample were $11.3 \%$ for whites and $10.5 \%$ for blacks (a 7.6\% difference). However, in the post-period, this quintuples in size, and white applicants receive $36 \%$ more callbacks than blacks do: the white callback rate is $15.0 \%$, and

\footnotetext{
${ }^{25}$ These robustness checks parallel those that we show for the triple-differences analysis in Table 7 below, which are explained in that section.

${ }^{26}$ In a separate draft paper, we further explore the geographic variations in the race effect. We find that businesses in whiter neighborhoods much more strongly favor white applicants, suggesting that New York City's greater racial diversity could partially explain why its race gap in callback rates is considerably smaller. Still, a substantial difference between the jurisdictions persists even after accounting for neighborhood racial composition. For a preliminary version of this analysis, see Agan and Starr (2016).

${ }^{27}$ The figure looks very similar if done only within the "perfect quad" sample.
} 
the black callback rate is $11 \%$. This figure does not take into account potential seasonal or temporal variation between the pre- and post-period unrelated to BTB; we address this possibility below.

\subsection{Triple-Differences Estimation Strategy}

To account for the possibility of seasonal variations or other secular trends that could confound our pre/post comparison, we employ a difference-in-difference-in-differences approach. This method exploits the fact that not all employers ask about criminal records even in the pre-BTB period (indeed, the majority do not). We treat such stores as a control group, comparing whether changes in the effects of race after BTB goes into effect differ between stores that have the box in the pre-period and those that do not. This will "difference out" effects of seasonal variation or other temporal differences unrelated to BTB, leaving us with an estimate of the causal effect of the BTB policy on employer callback difference by race or other characteristics of interest. Similarly, purely cross-sectional comparisons between employers with and without the box could be confounded by unobserved differences between those employers unrelated to the presence of the box. But the triple-differences analysis will difference out those unrelated differences as well, so long as they are time-invariant over the period in question.

This method implies the following general triple differences estimating equation:

$$
\begin{aligned}
\text { Callback }=\alpha & +\beta_{1} \text { White }+\beta_{2} \text { Post }+\beta_{3} \text { Treated }+\beta_{4} \text { White } x \text { Post } \\
& +\beta_{5} \text { White } x \text { Treated }+\beta_{6} \text { Post } x \text { Treated } \\
& +\beta_{7} \text { Treated } x \text { White } x \text { Post }+\epsilon
\end{aligned}
$$

Post is an indicator for the post-BTB period, Callback is an indicator for whether the applicant received a positive-response callback from the employer, Treated is an indicator for whether the company removed the box question after BTB. Treated is coded at the individual store level. Observations from a given store are coded as not treated (Treated $=0$ ) if the store never had "the box," and also in the rarer case of stores that had the box and failed to remove it after BTB. Observations are coded as treated if the store had the box but removed it after BTB. In most specifications, we also add a vector of control variables that accounts for the possibility of random imbalances in other applicant or application characteristics (GED, employment gap, criminal record, and geographic center).

In Equation (1) above, the main effect of interest is the triple-differences coefficient, $\beta_{7}$, which tells us how the employer callback gap for whites versus blacks changes differentially after 
BTB for treated versus non-treated stores. A positive coefficient implies that BTB favors white applicants relative to black applicants, that is, that treated employers become relatively more likely to call back white applicants after the box is removed.

An additional issue is that we did not apply to exactly the same set of stores or chains in the pre- and post-period - as discussed above, it was not always possible to send all four intended applications to each store. If the employers that we applied to in the post-period happened to have different patterns of discrimination from those in the pre-period (in a way that differed across treated and untreated employers), we could mistakenly interpret a compositional effect as an effect of BTB.

We have two approaches for addressing these compositional differences across periods. First, in some specifications, we substitute interacted chain fixed effects instead of some of the Treated terms in the equation above, as follows:

$$
\begin{aligned}
\text { Callback }= & +\beta_{1} \text { White }+\beta_{2} \text { Post }+\sum_{i=1}^{N} \beta_{3 i} \text { Chain }_{i}+\beta_{4} \text { White } x \text { Post }^{N} \\
& + \text { White } x \sum_{i=1}^{N} \beta_{5 i} \text { Chain }_{i}+\text { Post } x \sum_{i=1}^{N} \beta_{6 i} \text { Chain }_{i} \\
& +\beta_{7} \text { Treated } x \text { White } x \text { Post }+\epsilon
\end{aligned}
$$

where $i$ indexes chains, and Chain $_{i}$ represents a series of dummy variables for the chains in our sample. ${ }^{28}$ Because "treated" status occasionally varies between stores (usually because some chains give franchisees a choice of application platforms, or because a chain's BTB compliance differed between New Jersey and New York City), we assign separate Chain fixed effects to treated and untreated subsets of such chains. The result is that the Chain fixed effects perfectly parallel the Treated variable: Treated status follows directly from the Chain. The equation above substitutes the main effect of Treated with Chain fixed effects, and likewise substitutes Treated $x$ White $x$ Post with parallel sets of interacted fixed effects. However, it keeps the main effect of interest, the triple-differences estimate, in its easier-to-interpret form of Treated $x$ White $x$ Post. This term represents the average change in racial disparity due to BTB:

\footnotetext{
${ }^{28}$ The smallest chains (fewer than three locations or 12 total observations) are combined into industry-category groups; these chains represent about $9 \%$ of the sample. Original coding is used in a robustness check below.
} 
in effect, a weighted average of what the coefficients would be if White and Post were instead triply interacted with Chain, completing the substitution.

The chain-fixed-effects specifications account for differences in composition across periods by chain, but not by individual store (or by the geographic distribution of stores). Moreover, they do not provide easy-to-interpret coefficients on the main effects of White, Treated, and Post or their two-way interactions. We thus also offer a simpler approach for confronting the compositional differences: we conduct the analysis within the subset of stores to which we did send exactly four applications: one white/black pair in each period. Fortunately, we were usually able to do so; this "perfect quad" sample contains 11,118 observations, or $76 \%$ of our full sample. When using the perfect quad sample, the concerns about different distributions across chains, stores, or jurisdictions disappear (and no controls for these variables are necessary), because the sample is perfectly balanced between the pre- and post-periods. The simple triple-differences analysis can thus be used, and all the coefficients are easy to interpret; the disadvantage is some loss of power.

In any of these analyses, identification of $\beta_{7}$ as a causal effect relies on the assumption that, absent BTB, trends in employer callback differences by race would have been the same for treated and untreated stores (stores that had the box in the pre-period and those that did not). Unfortunately, our data are not long enough to compare pre-period trends. However, we believe the assumption is plausible. For a vast majority of stores in our sample (even those that are franchised), the job applications are standardized nationally at the chain level, with built-in variations accommodating local differences in BTB laws. ${ }^{29}$ Thus, the decision to include or not include the box on the application is made at the chain level, whereas callback decisions are made at the individual store level by store managers, or in some chains by local managers who supervise a small subset of locations. In that sense, whether a store has the box should be exogenous to the decision-makers we are studying. Moreover, there is no qualitative reason to believe that these chains differ in any way that would affect hiring trends in a racially disparate way. After all, to pose a threat to identification, hiring differences would have to be racially disparate in a way that differs over the time between our pre- and post-period applications (about four months on average). Note that not having the box does not generally reflect lack of interest in criminal records; chains with and

\footnotetext{
${ }^{29}$ For such chains, applications that normally have the box will usually either omit it if the store being applied to is in a BTB jurisdiction, or instruct the applicant not to answer the question if applying in certain jurisdictions.
} 
without the box, before and after BTB, routinely do back-end background checks (and their applications usually warn applicants of this fact).

\subsection{Triple-Differences: Raw Percentages}

Table 3 summarizes the changes in callback rates by race for treated and untreated stores before and after BTB went into effect. Each cell in Table 5 is itself a difference: the callback rate for black applicants minus the callback rate for white applicants. The "treated" column replicates what we already saw in Figure 2: at treated stores, the white advantage grew by 3.2 percentage points (from 0.8 percentage point to 4.0 percentage points) after BTB. But when we look at untreated stores, we do not see a similar change-indeed, if anything the white advantage actually declined slightly (but not statistically significantly). Thus the full triple-differences effect is a 3.7 percentage points increase in the black-white callback gap after BTB relative to untreated stores. This is a large increase, given that baseline callback rates are low; the average callback rate for black applicants in this sample is $10 \%$. If we restrict our analysis to the perfect quad sample, which is balanced on the chains and stores we applied to in the pre- and post-period, the triple-differences effect is similar and slightly larger: 4.2 percentage points.

\subsection{Triple-Differences Regressions}

Table 4 shows regression-adjusted triple-differences estimates across several specifications and samples. The effect of principal interest is on the top line,Post $x$ Treated $x$ White. Across specifications, the estimates are large, ranging from 3.6 to 4.1 percentage points (which amounts to a multifold increase in the underlying race gap). Our estimates here are somewhat less precise than the main-effects estimates discussed in Section 4, because triple-differences analyses demand much larger samples than analyses of main effects or even two-way interactions do in order to provide equivalent statistical power to estimate effects of a given size. Even so, all of these estimates are statistically significant $(\mathrm{p}<0.05)$, with $\mathrm{p}$-values generally around 0.04 . The estimates are similar to the unadjusted triple-differences estimates from Table 3.

Columns 1 and 2 show the simple triple-differences regression from Equation 1, with and without controls for the other randomized applicant characteristics (GED, employment gap, and criminal record) as well as center fixed effects. Adding these controls increases the tripledifferences coefficient slightly, from 3.7 to 4.1 percentage points. This analysis does not, however, account for the above-discussed differences in composition of the sample across time periods. We 
begin to address these in Column 3, which parallels Column 2 but substitutes interacted chain fixed effects for the Treated variable and its two-way interactions (per Equation 2). ${ }^{30}$ This analysis accounts for differences in the representation of the various chains in the pre- and post-period, and the main effect of interest declines slightly, to 3.6 percentage points.

Column 4 then further accounts for differences in the individual stores represented in the pre- and post-period samples by limiting the analysis to the "perfect quad" sample. In this sample chains and centers are perfectly balanced across time periods and race, so there is no reason to include the chain or center fixed effects. The effect estimate remains similar: 4 percentage points. In this perfect quad sample the estimated race gap at treated stores goes from 0.7 percentage points before BTB to 4.7 points after; comparing this to the baseline callback rate, whites receive $6.7 \%$ more callbacks than similar black candidates when employers are able to observe criminal records, but $45.2 \%$ more callbacks than similar black candidates when employers cannot observe records.

These analyses provide evidence that BTB increases racial discrimination in employer callbacks. Prior to the adoption of BTB, racial disparities are somewhat larger among the stores that do not have the box. After BTB, that difference flips. The growth in the "white" effect after BTB multiplies the race gap at affected stores by a factor of between five and seven; this factor varies slightly across specifications and samples, mainly because of variations in the small estimated preBTB race gap.

In Appendix A6, we recreate the above analysis substituting the GED and employment gap variables, respectively, for White in Equations (1) and (2). These characteristics are also correlated with criminal records, so one might expect the weight that employers place on them to also increase after BTB. The triple differences coefficients for both GED and employment gap, however, are not significant. For the employment gap the point estimates are nontrivial (around 2.5 percentage points; Table A5.2), albeit imprecise, and their signs go in the anticipated direction that statistical discrimination theory would predict: the negative effect of the employment gap increases when employers lose criminal record information. In the GED analysis, the point estimates are also negative but smaller, and very close to zero in the full-sample fixed-effect analysis (Table A5.1,

\footnotetext{
${ }^{30}$ It bears noting that the White, Post, and White $x$ Post estimates do not have a meaningful interpretation in this regression because the total effects of those variables are diffused among the interacted fixed effects.
} 
Col. 3). So we cannot characterize this as even suggestive evidence of statistical discrimination on the basis of the GED status.

\subsection{Alternative Specifications and Samples}

Tables $5 \mathrm{~A}$ and $5 \mathrm{~B}$ show robustness checks corresponding to our estimates for the full sample and the "perfect quad" sample respectively. Only the triple-differences coefficient is shown. For comparison purposes, Column 1 of both panels reproduces the corresponding mainspecification result - that is, the triple-differences coefficients from Columns 3 and 4 of Table 4, respectively. The coefficients and p-values are fairly similar for all variants except for columns 5 and 6 of each panel, which show results for New Jersey and New York City separately and are much less precise. In a few of the other specifications the p-values are above 0.05, but barely, representing only a small loss of precision or slightly reduced effect size; all p-values are between 0.04 and 0.06 , other than in the NJ-only and NYC-only regressions.

Column 2 in both panels replaces the callback outcome variable with the interview variable. In percentage point terms, the estimate becomes slightly smaller (but still significant) in the full sample, and is essentially unchanged in the "perfect quad" sample. However, because the recorded "interview" rate was much lower (6.3\% in the full sample), the effect on "interview" rates was actually quite a bit more dramatic in relative terms.

Columns 3 and 4 in both panels alter choices that we made about whether to exclude certain problematic observations. In Column 3, we add back in a small group that we had excluded: "reverse complier" stores that had no box before BTB, but (seemingly due to administrative mistakes) added it after BTB. Treated cannot be coded as 0 or 1 for these observations, but here we code it as -1 , reflecting the reversal of the usual treatment direction. ${ }^{31}$ The effect size is slightly smaller in both samples and the p-value is slightly above 0.05 in the perfect-quad specification. In Column 4, we exclude a small number of observations or quads (about $0.4 \%$ of each sample) in which an RA mistakenly answered a "box" question that she was not required to answer, or vice

\footnotetext{
${ }^{31}$ Note that the relationship between treatment and the passage of time is inverted for these observations, making this specification diverge from a standard triple-differences analysis. This is the main reason we excluded them.
} 
versa. ${ }^{32}$ Excluding them leaves both samples' estimates virtually unchanged, though the perfect quad sample p-value again rises slightly above 0.05 .

Columns 5 and 6 in both panels divide the sample between New Jersey and New York City, respectively. The large reduction in sample size renders these analyses underpowered for the purpose of estimating triple differences, and thus these estimates are quite imprecise (and should not be given much interpretive weight). In any event, although the New Jersey point estimate is larger in percentage-point terms, it is very similar in relative terms, once one accounts for New Jersey's substantially higher callback rate (14.9\% in the full sample, versus $9.4 \%$ in New York City). That is, although the estimates are imprecise, BTB appears to confer similarly large advantages on white applicants relative to black applicants in both jurisdictions.

In Panel A, Columns 7 and 8 show two additional variants on the full sample analysis that alter the chain fixed effects and their interactions; these variants are not relevant to the "perfect quad" analysis and are omitted from Panel B. In the main sample, the smallest chains (with under 12 observations total, or three stores) had been grouped based on business category (such as fast food restaurants or clothing stores). Column 7 instead uses individual chain fixed effects regardless of company size. Column 8, meanwhile, divides the chain fixed effects into New York and New Jersey subsets of each chain. Both changes add a large number of fixed-effect indicators to each regression and reduce precision slightly, but the point estimates remain similar.

Clustering in all regressions shown in the tables is on the chain, because whole chains are likely susceptible to serially correlated shocks. The chain also encompasses the smaller units according to which the applications we sent were grouped (the store, or sometimes a small group of stores). If one clusters on the geographic center instead (another dimension along which one could anticipate possible correlated shocks), the p-values for our main specifications are slightly higher in the full sample (0.054) and slightly lower in the perfect quad sample (0.024), and if one clusters on the individual store (ignoring correlations between chains), they are slightly higher in both samples (0.05 and 0.06, respectively).

\footnotetext{
${ }^{32}$ The main sample kept RA-error cases as long as the same error was made consistently within the store; we coded the treatment variable according to how the RA interpreted the application, since that tracked the information about criminal records that the RA provided or did not provide to the employer.
} 


\section{Discussion}

Our results produce mixed implications, and a potentially serious dilemma, for policymakers considering BTB laws. On the one hand, our results confirm BTB's basic premise: when employers ask about criminal records, having a record poses an obstacle to employment. Applicants without felony convictions received $63 \%$ more callbacks from employers with the box than identical applicants with felony convictions did. And this is despite the fact that these records were relatively minor (a single conviction of a nonviolent drug or property crime, more than two years prior), and the fact that the jobs we applied to are ones that one might expect to be comparatively welcoming to people with records. This finding is consistent with prior auditing studies (Pager 2003, Pager et al. 2009), but it is useful to confirm it in a newer, substantially larger sample and a new setting (online job applications) that is central to the modern job market.

The practical effect of the criminal-record penalty might be offset to some degree by the fact that most employers in the sectors we studied did not have the criminal-records box even before BTB. However, even when employers do not have the box on their applications, they are free (absent BTB) to ask about records at an interview and to check records at any time; even with BTB, they are free to do so later in the application process. Given that employers disfavor people with records, this effect may be present to some degree at later stages of the process even among nonBTB employers - stages our study does not assess, but could affect eventual employment outcomes.

However, our findings also provide evidence of a serious apparent unintended consequence of BTB: increased racial discrimination. BTB substantially increased the black-white gap in employer responses - indeed, by more than a factor of six in our main specifications. At BTBaffected employers, white applicants went from being $7 \%$ more likely to receive a callback than similar black applicants to being $45 \%$ more likely. This consequence is clearly unintended, as BTB is generally presented as a strategy for increasing access to employment for black men.

These results are consistent with the statistical discrimination theory put forward in Section 2. Although black men with records could be helped by BTB, this effect could be swamped by negative effects for black men without records if absent individualized information, employers tend to treat all black male applicants as if they have a high probability of having a record. That is, BTB removes the ability of black men without records to dispel employers' negative race-based assumptions. Meanwhile, if employers do not make the same negative assumptions about white 
male applicants (instead assuming that they are unlikely to have a record), white males with records would benefit from BTB, while white males without records would be unharmed. ${ }^{33}$

Consistent with this theory, we find gains for white male applicants as well as losses for black male applicants. At BTB-affected employers, after differencing out trends at unaffected employers, black applicants see their callback rates fall by two percentage points after BTB, while white applicants see theirs rise by two percentage points. To truly tease out which subsets of each group are affected, we would in principle want to add a fourth difference to our triple-differences analysis - that is, whether applicants have a record. We do not present such regression results here, not only because a quadruple-difference analysis would require an enormous sample to do precisely, but also because we cannot meaningfully code the criminal record variable when employers do not have the box.

However, the simple pre/post summary statistics for treated employers conveyed in Figure 2 provide a strong indication that, indeed, the principal beneficiaries of BTB (among the groups we studied) are white men with records, and that these gains come at the expense of black men without records. After BTB, callback rates for black applicants with records increase from $8.4 \%$ to $11 \%$ $(+2.6 \mathrm{pp}$, or a $31 \%$ increase); for white applicants with records they increase from $8.8 \%$ to $15 \%$ (+6.2 pp or a $70 \%$ increase). Callback rates for black applicants without records decrease $12.7 \%$ to $11 \%(-1.7 \mathrm{pp}$ or a $13 \%$ decrease); for white applicants without records they actually increase from $13.8 \%$ to $15 \%(+1.2$ pp or a $9 \%$ increase $) .{ }^{34}$ Note, however, that overall callback rates increased in our whole sample in the post-period, making this picture look generally rosier across the board. There is a 1.3 percentage-point increase in callbacks at untreated companies (and a 2.1 percentagepoint increase at treated companies). If we assume that at least these 1.3 percentage points reflect a secular rise unrelated to BTB, we should subtract them from the change for each group. This rough, back-of-the envelope analysis implies that white applicants without records are unaffected by BTB $(-0.1 p p$ change in callbacks after BTB, or $-1 \%)$, black applicants with records see some gain

\footnotetext{
${ }^{33}$ It is possible to imagine slightly more complicated theories that incorporate but are not limited to the statistical discrimination mechanism. For example, perhaps some employers refuse to hire either black applicants or applicants with records - and their bias against black applicants is grounded in pure prejudice unrelated to assumptions about criminal records. For black applicants to such employers, BTB would have no effect, but BTB would help white applicants with records by allowing them to take advantage of the racial advantage that other white applicants have. This theory does incorporate an aspect of statistical discrimination-employers must assume white applicants are unlikely to have records - but it also incorporates other discrimination mechanisms.

${ }^{34}$ For the post-period, these calculations apply the same averages to those with and without records because, in our experiment, these applicants became indistinguishable once employers no longer asked about records.
} 
$(+1.3 p p$, or $+15 \%)$, but black applicants without records see larger losses (-3pp, or $-24 \%)$ and white applicants with records see very large gains $(+4.9 \mathrm{pp}$, or $+56 \%){ }^{35}$

Even statistical discrimination amounts to illegal racial discrimination, and conflicts with the policy objective of expanding black male unemployment. The expansion of racial discrimination is thus plainly a negative unintended consequence of BTB. Nonetheless, one could still ask if the pattern we observe reflects accurate expectations by employers about who is likely to have a criminal records. Or are employers relying on inaccurate stereotypes about black criminality? While a complete answer would require making assumptions about the employer decision process with limited information, there is good reason to believe that employers are relying on assumptions that exaggerate real-world racial differences in conviction rates. Although absolute black/white differences in felony conviction rates are large (Shannon et al. 2011), they are much smaller once one conditions on other applicant characteristics that employers can observe. Our calculations from the National Longitudinal Survey of Youth 1997 (NLSY97), the best available data source that we have identified, ${ }^{36}$ show that amongst men between the ages of 18 and 25 without any higher education degrees, $29.4 \%$ of black men had a criminal conviction, whereas $24.7 \%$ of white men did. Our black and white applicants are identical on a range of other characteristics as well-work history, neighborhood, and so forth - which one would expect to narrow the gap further. And yet employers who were provided with a individualized information about these characteristics nonetheless gave considerable weight to race as a predictor of criminality.

One possibility is that employers engage in statistical discrimination in a far less nuanced way than rational-choice economic theory would predict-they may rely on a general impression that black rates of involvement with the criminal justice system are higher in absolute terms, without any specific sense of whether these differences persist after conditioning on the relevant set of observed characteristics. It would not be surprising if employers made assumptions about black applicants' likely criminality, even if those assumptions are not well founded in fact. Lab experiments on implicit biases have consistently found that most Americans make such assumptions subconsciously (see, for example, Eberhardt 2004; Nosek et al. 2007), and such mechanisms may

\footnotetext{
${ }^{35}$ Note that the Figure 2 numbers actually slightly understate the increase in the race gap that we found in the tripledifferences regression analysis (that is, after differencing out racially specific trends at unaffected companies, rather than merely the overall trend, the increase in racial disparity looks even larger).

${ }^{36}$ Few surveys collect data about criminal convictions. The NLSY97 is unusual in that it does provide self-reported criminal convictions as well as information about a range of other variables, although its sample size is fairly small (Brame et al. 2014).
} 
not involve an accurate comparison of conditional probabilities. Bordalo et al. (2016) offer a more general theoretical model for how generalizations based on a "kernel of truth" (such as higher black conviction rates) may become greatly exaggerated in the eyes of decision-makers.

Further support for the inference that employer expectations about racial differences in conviction rates are exaggerated comes from the contrast with our results on the GED versus high school diploma distinction; we did not find that BTB significantly increased the weight employers placed on having a GED. Nor, indeed, do employers place significant weight on this variable at all, even at non-box stores. And yet having a GED in lieu of a diploma is actually a much stronger predictor of criminal convictions than race is, conditional on the same observables. In the NLSY97, among young men with no college degrees, $43 \%$ of those with a GED have a conviction by age 25 , whereas only $18 \%$ of those with a high school diploma have one. This contrast suggests that whatever employers' cost-benefit calculus about interviewing people with records, they must either be irrationally overweighting race as a signal, underweighting education, or both.

We believe that the randomized experimental design, in combination with the tripledifferences analysis, provides a strong basis for interpreting our estimates as causal effects of BTB. The randomization means that we avoid most of the potential interpretive challenges that observational researchers encounter: our black and white applicants to all business types in all locations and periods have the same qualifications and characteristics. Any remaining threats to identification would have to come from unobserved differences that (1) affect applicants to treated and untreated businesses differently (2) in ways that differ by race (among otherwise-identical applicants) and (3) this difference must differ across time periods as well. Although it is of course possible that (independent of BTB) some such difference might exist, there is no obvious candidate for what it might be. This is especially so because the time period between the pre- and postperiods is just a few months, because the groups of businesses are of similar types and sizes, and because we see approximately the same triple-differences effect in New Jersey and New York City, even though the pre- and post-periods in those two jurisdictions were seasonally nearly opposite to one another. ${ }^{37}$

One alternative causal theory is that BTB might affect applicant pools at treated companies, by encouraging more applicants with records to apply. If this is so, then even though our fictional

\footnotetext{
${ }^{37}$ In New Jersey we went from winter to late spring/early summer; in New York we went from summer to winter.
} 
applicants are the same in both periods, their competition is not, potentially affecting callback rates. But to explain the large increase in discrimination by race, changes in the competition would have to affect our black and white applicants differently. If the mechanism involves statistical discrimination based on assumptions about records, then it is simply a variant on the theories we have already proposed. Indeed, whatever employers' reasoning, if the theory is that BTB causes changes in the applicant pool that somehow cause employers to treat black applicants more adversely than identical whites, then it does not threaten our causal inference that BTB increases racial discrimination - it merely provides another mechanism by which it might do so. ${ }^{38}$

In any event, the effect of BTB on applicant pools (of either set of employer) may well be mitigated if applicants do not know what employers have the box before they are nearly done with the application (the box usually appears as one of the last screens). Some applicants with records might well gain such information before applying, but we suspect that this knowledge is at least not ubiquitous, in part because we ourselves (despite considerable effort) were unable to find resources listing employers with and without the box prior to conducting our resource-intensive data collection. Applicants would also have to know about BTB, as well as its effective date.

Another possible concern is that because BTB restricts interview questions (not just application questions), it possible that it could encourage even "untreated" employers to statistically discriminate as well: knowing that they cannot ask records questions in the interview might make them less likely to interview candidates that they think might have records. If anything this possibility should mean our triple-differences estimate is downward biased, because BTB encourages statistical discrimination at both sets of employers, while we are measuring only the difference.

One limitation of our study is that we are unable to study the effect of BTB (or of criminal record or race) on actually getting a job, only initial employer responses. If firms are reluctant to

\footnotetext{
${ }^{38} \mathrm{~A}$ variant of this concern is that BTB might affect untreated businesses' applicant pools in some way (presumably reducing the number of applicants with records, as they apply to treated businesses instead) that leads them to increase callbacks of black applicants relative to whites. There are several reasons to doubt that this can explain our results. First, the estimates in Table 3 strongly suggest that the triple-differences effect is being driven almost entirely by an increase in racial disparity among treated employers, not a reduction among untreated employers. Second, changes to the untreated employers' applicant pool are likely to be relatively subtle, because for many (probably most) applicants there is no necessary tradeoff between applying to treated and untreated businesses. Third, given that the untreated employers lack the box both before and after BTB, it seems that many would be unlikely to notice changes in the percentage of their applicants with records, especially if those changes are not drastic. Employers would have to notice or anticipate such a change, and update their race-specific expectations and decision-making accordingly, very quickly in order to affect our results, given that the post-period is very shortly after BTB.
} 
hire applicants with a record even after they "get their foot in the door," BTB may not change employment rates (for a similar point on discrimination against the long-term unemployed, see Jarosch and Pilossoph (2016)). While this is a substantial limitation, BTB is meant precisely to impact the initial stage of the hiring process; thus, it is important to understand whether and for whom doors are open or shut at this initial stage. If black applicants with no records lose their ability to get their foot in the door, this is an important unintended consequence regardless of what the ultimate effects of BTB are for people with records.

\section{Policy Implications}

BTB may open doors to some applicants with records, but this gain comes at the expense of another group that faces serious employment challenges: black men. BTB is often presented as a way of increasing black male employment, but most black men do not have criminal convictions, and BTB risks harming black men without records by preventing them from signaling that fact to employers. This is a serious unintended consequence, but it is not necessarily dispositive as to BTB's merits. Policymakers will have to evaluate how to weigh this risk versus BTB's potential benefits, and also to consider whether there are strategies that could simultaneously be pursued that might successfully mitigate this disadvantage.

Even if one simply wishes to evaluate BTB's race-related effects (setting aside other policy concerns), the picture is somewhat complex. While in our sample BTB's apparent effect on the race gap was fairly dramatic, an important unanswered question is how large an effect this phenomenon will have on real world job applicants. One limitation of auditing studies generally is that they do not directly provide estimates of changes in actual markets (Heckman and Siegelman 1993; Heckman 1998). In the real world, applicants are not divided 50/50 between identical black male and white male candidates (and no other groups), with $50 \%$ of each group having a record. Our study suggests that BTB should be expected to substantially help applicants with records, at least at the initial callback stage, and in the real world black men have records at higher rates. This point means that even if BTB increases racial discrimination by employers, it does not necessarily follow that it will increase racial disparity in employment on balance. It could simultaneously be true that BTB helps black men with records (by eliminating record-based discrimination in callbacks), while hurting black men without records (by increasing racial discrimination), and the net effect on black male employment would depend on the size of each effect and the size of the respective groups they affect. And this calculus may vary as BTB is applied to different markets and places-employers' 
treatment of both race and criminal records may vary considerably, as our comparisons of New Jersey and New York City illustrate.

That said, some back-of-the-envelope calculations suggest that at least in contexts similar to the one we studied, the net effect is to enlarge the black-white employment gap. Consider again 25year-old men without college degrees: per the NLSY97, the black and white conviction rates are $29.4 \%$ and $24.7 \%$, respectively. Suppose all such men were subject to changes in employer callback rates paralleling the pattern in Figure 2 (the raw changes at treated employers) - a pattern that actually slightly understates the growth in racial discrimination that our triple-differences regression analyses found. As discussed in Section 6, Figure 2 (after adjusting for the secular rise in callback rates observed at untreated companies) implies that black men with and without records would see changes in callback rates of +1.3 and -3.0 percentage points, respectively, while white men with and without records would see changes of +4.9 and -0.1 percentage points, respectively. Applying these changes to the real-world distribution of records from the NLSY97 implies that overall black callback rates would fall by 1.7 points, while overall white callback rates would rise by 1.1 points - a net rise of 2.8 percentage points in the black-white callback rate gap (about a quarter of the overall callback rate for our sample, and four times the underlying pre-BTB blackwhite gap).

This example suggests that even after offsetting the effect of eliminating criminal-recordbased discrimination, the increase in racial disparity due to BTB could be considerable. In addition to the differential effects on white and black applicants without records, part of the reason for this is that it is white applicants with records who benefit much more substantially from BTB than black applicants with records do. ${ }^{39}$ Of course, a full analysis of real world effects would have to account for the fact that white and black men may have different distributions of other characteristics as well (beyond criminal records), and for the fact that they are not the only two groups competing for jobs. We chose to focus on white and black men because further subdividing the sample would have presented challenges in terms of statistical power. But women and men of other racial groups could be affected, and such effects could be avenues of future research. Moreover, while auditing studies

\footnotetext{
${ }^{39}$ One complicating factor is that not every applicant in the real world has a racially distinctive name (only about half do), perhaps reducing the relative impact of the racial-discrimination effect in comparison to the record-discrimination effect. However, this point may be offset by the fact that real-world applicants may also have other signals of likely race on their job applications, such as their neighborhood of residence or high school; our fictional applications included no such signals, as everything was randomized among a set of fairly race-neutral options.
} 
point to a mechanism, observational studies can help to further explore how that mechanism plays out given the actual distribution of candidates.

Policymakers might also consider whether there are other interventions that BTB could be combined with to reduce its adverse effects on black candidates. Race-based statistical discrimination in hiring is unlawful, and if hiring discrimination laws were effectively enforced or operated as an effective deterrent, BTB would not have this unintended consequence. This, to be sure, is easier said than done. The intuition behind BTB perhaps suggests one potential innovation: asking employers to blind themselves to names (and other potentially racially identifying information unrelated to job qualifications, such as home addresses) in addition to records. Whether such an approach would succeed in changing hiring patterns is an open empirical question, however chains wishing to reduce racial discrimination in employment could experiment with trying this approach voluntarily. Another possibility is to alter employers' underlying incentives to encourage them to want to hire people with records, perhaps through expansion of tax incentives or reductions in employer liability due to negligent hiring lawsuits. ${ }^{40}$

The racial-disparity implications are not the only policy consideration surrounding BTB, and whether our results imply that the policy is unsuccessful depends, of course, on what policymakers seek to maximize. To the extent that advocates and policymakers hoped this BTB would reduce racial inequality in employment opportunities, it appears to be doing quite the opposite. However, policymakers might reasonably endorse it nonetheless, on the ground that people with records are a group in acute need of a leg up, regardless of race. If jobs discourage crime, society may also have a special interest in providing that help for public safety reasons. Our study does not seek to inform every aspect of the policy debate surrounding BTB, but we do find that as a racial-disparityreduction strategy, it has unintended consequences.

\footnotetext{
${ }^{40}$ A non-representative survey of HR professionals conducted by the Society for Human Resource Management (2012) showed that one of the primary reasons companies perform background checks was to reduce legal liability for negligent hiring (55\% in 2010 and $52 \%$ in 2010$)$.
} 


\section{References}

Aigner, D.J. and Glen G. Cain. (1977). "Statistical Theories of Discrimination in Labor Markets", Industrial and Labor Relations Review 30.

Arrow, K. (1973). The Theory of Discrimination. In Discrimination in Labor Markets Ashenfelter, O. and A. Rees (Eds) Princeton University Press, 3-33.

Autor, D.H. and D. Scarborough. (2008). "Does Job Testing Harm Minority Workers? Evidence from Retail Establishments," The Quarterly Journal of Economics 123(1): 219-277.

Bartik, A. and S. Nelson. (2016). "Credit Reports as Resumes: The Incidence of Pre-Employment Credit Screening”, MIT Department of Economics Graduate Student Research Paper 16-01

Bertrand, M. and S. Mullainathan. (2004). "Are Emily and Greg More Employable Than Lakisha and Jamal? A Field Experiment on Labor Market Discrimination", American Economic Review 94(4): 991-1013

Bordalo, Pedro, et al. (2016). "Stereotypes." Quarterly Journal of Economics (forthcoming). Working paper: http://scholar.harvard.edu/files/shleifer/files/stereotypes_bcgs_feb25_paper.pdf.

Brame, R., S.D. Bushway, R. Paternoster and M. G. Turner. (2014). "Demographic Patterns of Cumulative Arrest Prevalence by Ages 18 and 23," Crime \& Delinquency 60(3): 471-486.

Bushway, S. (2004). "Labor Market Effects of Permitting Employer Access to Criminal History Records," Journal of Contemporary Criminal Justice. Special Issue on Economics and Crime 20: 276-291.

Center for Health Statistics, Birth/EBC Confidential Data Files, New Jersey Department of Health, Trenton, NJ

City of New York (Jan 2016), "Young Men's Initiative: Justice" http://www.nyc.gov/html/ymi/html/justice/justice.shtml\#ban

Clarke, H. (December 20, 2012). "Protecting the Rights of Convicted Criminals: Ban the Box Act of 2012" Washington Post.

Clifford, R. and Shoag, D. (2016). "No More Credit Score: Employer Credit Check Bans and Signal Substitution" Unpublished Manuscript

Color of Change (November 2, 2015). "Civil Rights Group Responds to the 'Ban the Box' Executive Order" http://colorofchange.org/press/releases/2015/11/2/civil-rights-group-respondsban-box-executive-orde/

Community Catalyst. (December 2, 2013). Banning the Box in Minnesota-and across the United States, http://www.communitycatalyst.org/blog/banning-the-box-in-minnesota-and-across-theunited-states\#.UuG1 Yo46U.

Decker, S., E. Hedberg, and C. Spohn. (2015) "Criminal stigma, race, and ethnicity: The consequences of improsionment for employment" Journal of Criminal Justice 43: 108-121

Deming, D., N. Yuchtman, A. Abulafi, C. Goldin and L. Katz (September 2014). "The Value of Postsecondary Credentials in the Labor Market: An Experimental Study," NBER WP \#20528

Doleac, J. and B. Hansen (2016) 'Does 'ban the box' help or hurt low-skilled workers? Statistical discrimination and employment outcomes when criminal histories are hidden" Unpublished 
manuscript. content/uploads/2015/03/Doleac_Hansen_BanTheBox.pdf

http://jenniferdoleac.com/wp-

Equal Employment Opportunity Commission (EEOC). (2012). EEOC Enforcement Guidance 915.002. Consideration of Arrest and Conviction Records under Title VII of the Civil Rights Act of 1964.

Eberhardt, J.L. et al. 2004. "Seeing Black: Race, Crime, and Visual Processing," Journal of Personality and Social Psychology 87:876.

Fang, H. and A. Moro. (2011). "Theories of Statistical Discrimination and Affirmative Action: A Survey" in Handbooks in Economics: Social Economics eds J. Benhabib, M. Jackson, and A. Bisin

Farber, H., D. Silverman, and T. von Wachter. (2015, Sept 17) "Factors Determining Callbacks to Job Applications by the Unemployed: An Audit Study" Unpublished Manuscript. Accessed at: http://www.irs.princeton.edu/sites/irs/files/event/uploads/audit hf09.pdf

Finlay, K. (2009). "Effect of Employer Access to Criminal History Data on the Labor Market Outcomes of Ex-Offenders and Non-Offenders", in Studies of Labor Market Intermediation, 89 (David H. Autor, ed.).

Finlay, K. (2014). "Stigma in the Labor Market”, Unpublished Manuscript

Freeman, R. (2008). “ Incarceration, Criminal Background Checks, and Employment in a Low(er) Crime Society," Criminology \& Public Policy 7: 405-412

Fryer, R.G. Jr and S.D. Levitt (2004). "The Causes and Consequences of Distinctly Black Names", The Quarterly Journal of Economics 119(3): 767-805

Heckman, J.J. (1998) “Detecting Discrimination”, Journal of Economic Perspectives 12(2): 101116

Heckman, J.J. and P.A. LaFontaine. (2010). "The American High School Graduation Rate: Trends and Levels" Review of Economics and Statistics 92(2): 244-262.

Heckman, J., and P. Siegelman (1993). "The Urban Institute Audit Studies: Their Methods and Findings," in ed. M. Fix and R. Struyk, Clear and Convincing Evidence: Measurement of Discrimination in America, 187-258.

Holzer, H.J. (2007). "Collateral Costs: The Effects of Incarceration on the Employment and Earning of Young Workers” IZA Discussion Paper No. 3118

Holzer, H.J., S. Raphael and M.A. Stoll (2006). "Perceived Criminality, Criminal Background Checks, and the Racial Hiring Practices of Employers, "Journal of Law and Economics 49:451.

Jarosch, G. and L. Pilossoph (2016). "Statistical Discrimination and Duration Dependence in the Job Finding Rate" Unpublished Manuscript

Kroft, K., F. Lange and M. Notowidigdo (2013). "Duration Dependence and Labor Market Conditions: Evidence from a Field Experiment," Quarterly Journal of Economics 128(3): 11231167

Lahey, J. (2008). "Age, Women, and Hiring: An Experimental Study," Journal of Human Resources 43(1): 30-56. 
Lahey, J. and R. Beasley (2009). "Computerizing Audit Studies," Journal of Economic Behavior and Organization 70(3): 508-514

List, J. (2004). "The Nature and Extent of Discrimination in the Marketplace: Evidence from the Field," The Quarterly Journal of Economics 119(1): 48-89

Love, M. (2011). "Paying Their Debt to Society: Forgiveness, Redemption, and the Uniform Collateral Consequences of Conviction Act," Howard Law Journal 54(3): 753-793

Minnesota Department of Human Rights (2015), "Ban The Box: Overview for Private Employers" http://mn.gov/mdhr/employers/banbox overview privemp.html Last Accessed Jan 19, 2016.

NAACP (2014, Jan). Our Accomplishments, http://www.naacp.org/pages/2106.

Neumark, D. (1996), "Sex Discrimination in Restaurant Hiring: An Audit Study", The Quarterly Journal of Economics 111(3): 915-941.

Neumark, D. (2012) "Detecting Discrimination in Audit and Correspondence Studies", The Journal of Human Resources 47(4): 1128-1157

Neumark, D., I. Burn, and P. Button (2015) "Is it Harder for Older Workers to Find Jobs? New and Improved Evidence from a Field Experiment” NBER WP 21669

Nosek, B.A. et al. (2007) "Pervasiveness and Correlates of Implicit Attitudes and Stereotypes," European Review of Social Psychology 2007:1.

Oreopoulos, P. (2011). "Why Do Skilled Immigrants Struggle in the Labor Market? A Field Experiment with Thirteen Thousand Resumes," American Economic Journal: Economic Policy 3(4): 148-71.

Pager, D. (March 2003). "The Mark of a Criminal Record," American Journal of Sociology 108(5): 937-975.

Pager, D., B. Western, \& B. Bonikowski. (2009). "Discrimination in a Low-Wage Labor Market," American Sociological Review, 74:777-799.

Phelps, Edmund S. (1972). "The Statistical Theory of Racism and Sexism”, American Economic Review. 62:659.

Phillips, D. C. (April 2016). "Do Low-Wage Employers Discriminate Against Applicants with Long Commutes? Evidence from a Correspondence Experiment” Unpublished Manuscript

Pinard, M. (January 7, 2014). "Ban the Box in Baltimore," Baltimore Sun.

Reaves, B. (December 2013). "Felony Defendants in Large Urban Counties, 2009 - Statistical Tables” US Department of Justice Bureau of Justice Statistics Report NCJ 243777

Riach, P.A. and J. Rich (2002). "Field Experiments in Discrimination in the Market Place", The Economic Journal 112(483): F480-F518

Rodriguez, M and B. Avery. (April 2016). "Ban The Box: U.S. Cities, Counties, and States Adopt Fair-Chance Policies to Advance Employment Opportunities for People with Past Convictions". National Employment Law Project Guide Accessed June 9, 2016 : http://www.nelp.org/publication/ban-the-box-fair-chance-hiring-state-and-local-guide/

Shannon, S., C. Uggen, M. Thompson, J. Schnittker, and M. Massoglia (2011). "Growth in the U.S. Ex-Felon and Ex-Prisoner Population, 1948-2010" Unpublished Manuscript 
Shoag, D. and S. Veuger (2016) "No Woman No Crime: Ban the Box, Employment, and Upskilling" Unpubslihed Manuscript

Society for Human Resource Management. (July 19 2012). Background Checking - the Use of Criminal Background Checks in Hiring Decisions.

Southern Coalition for Social Justice. (2013). Ban the Box Community Initiative Guide, http://www.southerncoalition.org/program-areas/criminal-justice/ban-the-box-communityinitiative-guide/.

Starr, S. (2015). "Do Ban the Box Laws Reduce Employment Barriers for Black Men?" Unpublished Manuscript.

Stoll, Michael A. (2009). Ex-Offenders, Criminal Background Checks, and Racial Consequences in the Labor Market, 1 Univ. of Chicago Legal Forum 381 (2009).

Uggen, C., M. Vuolo, S. Lageson, E. Ruhland, and H. Whitham (2014). "The Edge of Stigma: An Experimental Audit of the Effects of Low-Level Criminal Records on Employment" Criminology 52(4): 627-654.

Wozniak, A. (2015, July). "Discrimination and the Effects of Drug Testing on Black Employment". The Review of Economics and Statistics 97(3): 548-566 
Figure 1: Callback Rates by Race, Crime, and Box: Pre-Period Applications Only

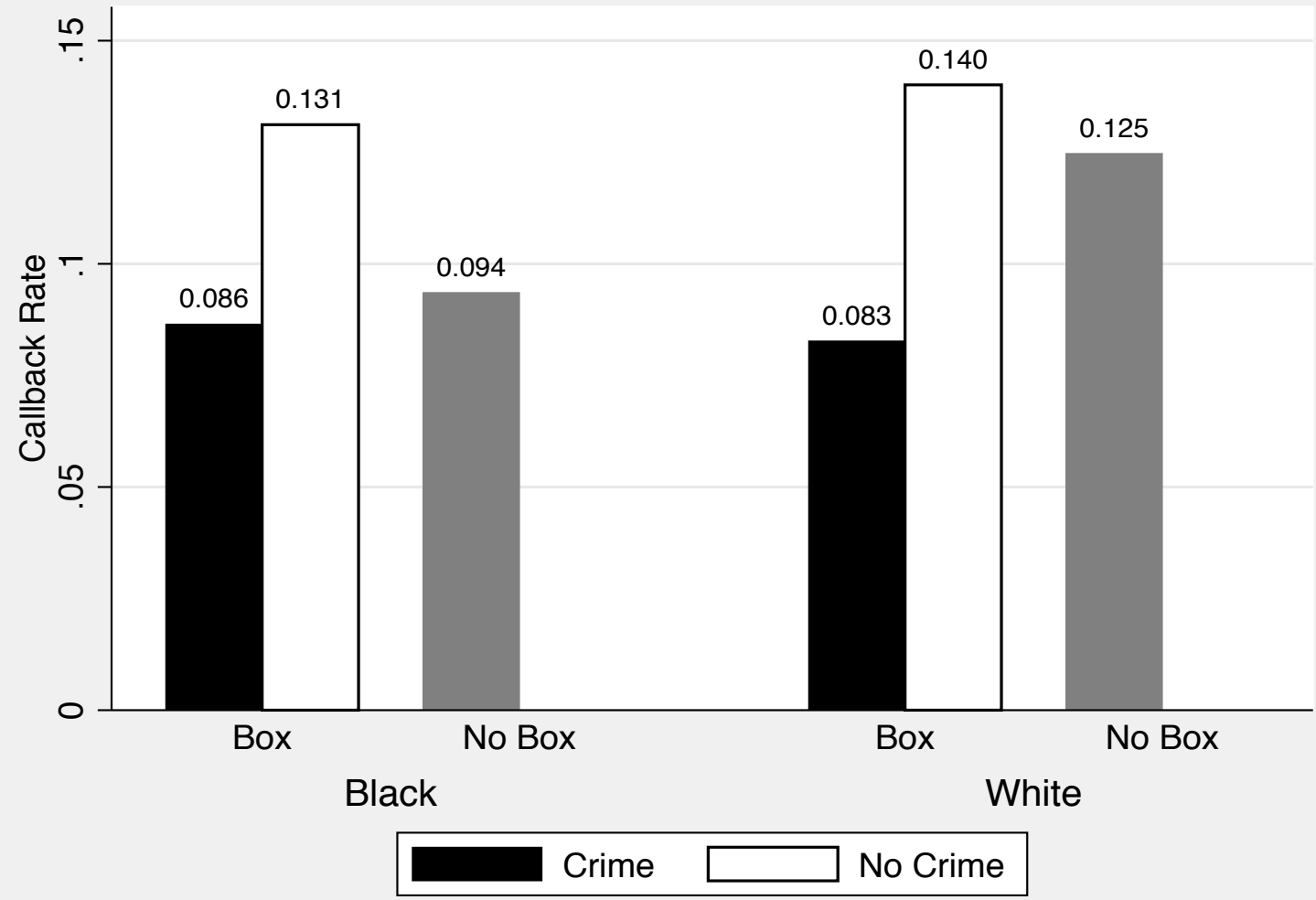

Notes: This figure compares callback rates within the pre-period before Ban the Box goes into effect, comparing applications with the box (application which ask about criminal records) and those without (applications that do not ask about criminal records). A callback is a personalized phone call or e-mail to the applicant requesting follow-up contact or an interview. 
Figure 2: Callback Rates by Race, Criminal Record, and Period: Treated Only

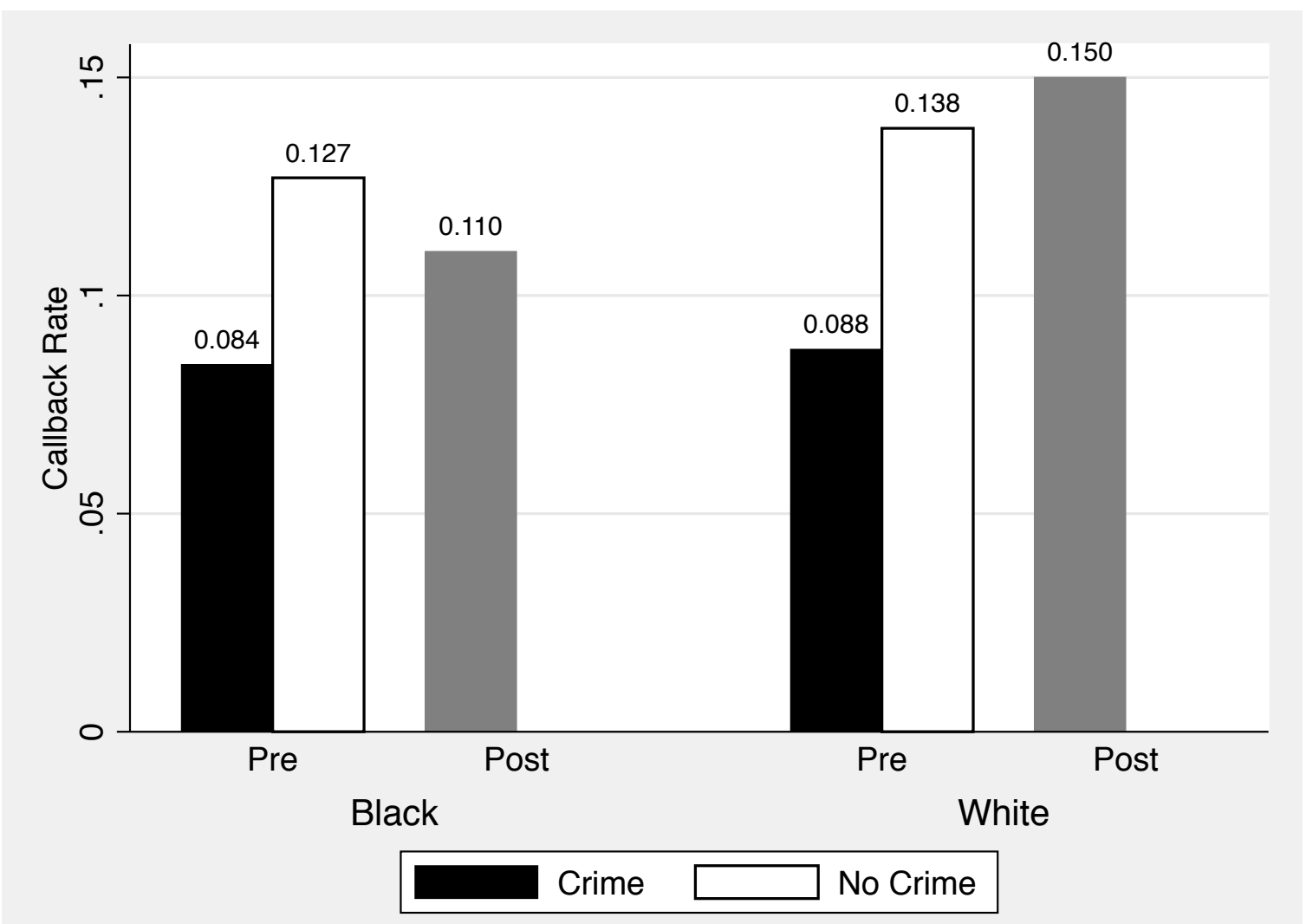

Notes: This figure compares callback rates within treated companies, i.e. those companies that asked the criminal record question in the pre-period, before and after Ban the Box goes into effect. A callback is a personalized phone call or e-mail to the applicant requesting follow-up contact or an interview. 
Table 1a: Means of Applicant and Application Characteristics and Callback Rates by Period

\begin{tabular}{llll}
\hline & Pre-Period & Post-Period & Combined \\
\hline Characteristics: & & & \\
White & 0.502 & 0.497 & 0.500 \\
Crime & 0.497 & 0.513 & 0.505 \\
GED & 0.498 & 0.502 & 0.500 \\
Employment Gap & 0.492 & 0.504 & 0.498 \\
Application has Box & 0.366 & 0.036 & 0.199 \\
& & & \\
Results: & & & \\
Callback Rate & 0.109 & 0.125 & 0.117 \\
Interview Req & 0.060 & 0.067 & 0.063 \\
& & & \\
Callback Rate & by & & \\
Characteristics: & & & \\
Black & 0.099 & 0.111 & 0.105 \\
White & 0.120 & 0.139 & 0.129 \\
GED & 0.106 & 0.127 & 0.117 \\
HSD & 0.113 & 0.122 & 0.118 \\
Emp Gap & 0.110 & 0.126 & 0.118 \\
No Emp Gap & 0.109 & 0.124 & 0.116 \\
\hline Observations & 7246 & 7394 & 14640 \\
\hline
\end{tabular}

Notes: Callback implies application received a personalized positive response from the employer (either via phone or e-mail). Interview request means the positive response specifically mentioned an interview. Application has box means that the application asked about criminal records. Employment (emp) gap is a 1113 month employment gap in work history, no emp gap is a 0-2 month gap.

Table 1b: Callback Rates by Crime Status for Stores with the Box in the Pre-Period

\begin{tabular}{llllll}
\hline & No Crime & Crime & Property & Drug & Combined \\
\hline Callback Rate & 0.136 & 0.085 & 0.084 & 0.085 & 0.110 \\
Callback Black & 0.131 & 0.086 & 0.091 & 0.081 & 0.109 \\
Callback White & 0.140 & 0.083 & 0.077 & 0.089 & 0.111 \\
\hline Observations & 1319 & 1336 & 703 & 633 & 2655 \\
\hline
\end{tabular}

Notes: Sample restricted to pre-period applications where the application asked about criminal records. Callback implies application received a personalized positive response from the employer. 
Table 2: Effects of Applicant Characteristics on Callback Rates

\begin{tabular}{|c|c|c|c|c|c|c|}
\hline & (1) & (2) & (3) & (4) & (5) & (6) \\
\hline White & $\begin{array}{l}0.0244 * * * \\
(0.0057)\end{array}$ & $\begin{array}{l}0.0239 * * * \\
(0.0054)\end{array}$ & $\begin{array}{l}0.0297 * * * \\
(0.0070)\end{array}$ & $\begin{array}{l}-0.0010 \\
(0.0093)\end{array}$ & $\begin{array}{l}-0.0012 \\
(0.0093)\end{array}$ & $\begin{array}{l}0.0065 \\
(0.0149)\end{array}$ \\
\hline Crime & $\begin{array}{l}-0.0161 * * * \\
(0.0053)\end{array}$ & $\begin{array}{l}-0.0136^{* *} \\
(0.0054)\end{array}$ & & $\begin{array}{l}-0.0520^{* * * *} \\
(0.0121)\end{array}$ & & $\begin{array}{l}-0.0444 * * * \\
(0.0134)\end{array}$ \\
\hline GED & $\begin{array}{l}-0.0014 \\
(0.0052)\end{array}$ & $\begin{array}{l}-0.0041 \\
(0.0048)\end{array}$ & $\begin{array}{l}-0.0076 \\
(0.0056)\end{array}$ & $\begin{array}{l}0.0096 \\
(0.0134)\end{array}$ & $\begin{array}{l}0.0097 \\
(0.0132)\end{array}$ & $\begin{array}{l}0.0097 \\
(0.0134)\end{array}$ \\
\hline Emp. Gap & $\begin{array}{l}0.0012 \\
(0.0048)\end{array}$ & $\begin{array}{l}0.0017 \\
(0.0046)\end{array}$ & $\begin{array}{l}0.0005 \\
(0.0050)\end{array}$ & $\begin{array}{l}0.0103 \\
(0.0101)\end{array}$ & $\begin{array}{l}0.0104 \\
(0.0100)\end{array}$ & $\begin{array}{l}0.0102 \\
(0.0101)\end{array}$ \\
\hline Pre-Period & & $\begin{array}{l}-0.0149 \\
(0.0096)\end{array}$ & & & & \\
\hline Drug Crime & & & & & $\begin{array}{l}-0.0501^{* * *} \\
(0.0133)\end{array}$ & \\
\hline Property Crime & & & & & $\begin{array}{l}-0.0536^{* * *} \\
(0.0143)\end{array}$ & \\
\hline White $\mathrm{x}$ Crime & & & & & & $\begin{array}{l}-0.0149 \\
(0.0171)\end{array}$ \\
\hline Constant & $\begin{array}{l}0.1132 * * * \\
(0.0156)\end{array}$ & $\begin{array}{l}-0.0069 \\
(0.0261)\end{array}$ & $\begin{array}{l}0.0016 \\
(0.0291)\end{array}$ & $\begin{array}{l}-0.0134 \\
(0.0538)\end{array}$ & $\begin{array}{l}-0.0133 \\
(0.0539)\end{array}$ & $\begin{array}{l}-0.0184 \\
(0.0537)\end{array}$ \\
\hline Observations & 14640 & 14640 & 11722 & 2918 & 2918 & 2918 \\
\hline Sample & All & All & Non-Box & Box & Box & Box \\
\hline Chain FE & No & Yes & Yes & Yes & Yes & Yes \\
\hline Center FE & No & Yes & Yes & Yes & Yes & Yes \\
\hline
\end{tabular}

Notes: Dependent variable is whether the application received a callback. Standard errors clustered on chain in parentheses. The non-box sample includes only applications that did not ask about criminal history; the box sample includes only those applications that asked about criminal records. Chain and center fixed effects are included in Columns (2) - (6) as indicated. White is as compared to black applicants, crime is as compared to no-crime, GED is as compared to a HS Diploma and Emp. Gap is a 11-13 month gap in work history as compared to a 0-2 month gap. 
Table 3: Average Black-White Response Rate Differences by Race and Treated, Before and After BTB Goes into Effect in NJ

\begin{tabular}{lccc}
\hline & Treated & Not Treated & Diff \\
Black - White Callback Rate, Pre & -0.008 & -0.027 & 0.019 \\
Black - White Callback Rate, Post & -0.040 & -0.022 & -0.018 \\
\cline { 4 - 4 } Diff & 0.032 & -0.005 & 0.037 \\
\hline Diff, Perfect Quad Sample & 0.038 & -0.004 & 0.042 \\
\hline
\end{tabular}

Notes: Each cell is a black-white response rate differential, measured in percentage points. The last line restricts analysis to only those stores in the "perfect quad" sample, that is, stores for which we sent two applications in the pre- and two in the post. The two outlined cells represent the raw triple-differences in the full sample and the perfect quad sample. A treated store is one that had the box in the pre-period and then removed it due to BTB. 
Table 4: Effects of Ban the Box on Racial Discrimination, Triple Difference Specification

\begin{tabular}{|c|c|c|c|c|}
\hline & (1) & (2) & (3) & (4) \\
\hline Post $\mathrm{x}$ Treated $\mathrm{x}$ White & $\begin{array}{l}0.0371^{* *} \\
(0.0180)\end{array}$ & $\begin{array}{l}0.0409^{* *} \\
(0.0184)\end{array}$ & $\begin{array}{l}0.0358^{* *} \\
(0.0180)\end{array}$ & $\begin{array}{l}0.0399^{* *} \\
(0.0200)\end{array}$ \\
\hline Post $\mathrm{x}$ White & $\begin{array}{l}-0.00530 \\
(0.0125)\end{array}$ & $\begin{array}{l}-0.00627 \\
(0.0123)\end{array}$ & $\begin{array}{l}-0.00618 \\
(0.0128)\end{array}$ & $\begin{array}{l}-0.00236 \\
(0.0136)\end{array}$ \\
\hline Post $x$ Treated & $\begin{array}{l}-0.0102 \\
(0.0177)\end{array}$ & $\begin{array}{l}-0.0115 \\
(0.0177)\end{array}$ & & $\begin{array}{l}-0.0198 \\
(0.0214)\end{array}$ \\
\hline White $\mathrm{x}$ Treated & $\begin{array}{l}-0.0187 \\
(0.0140)\end{array}$ & $\begin{array}{l}-0.0213 \\
(0.0140)\end{array}$ & & $\begin{array}{l}-0.0175 \\
(0.0146)\end{array}$ \\
\hline Treated & $\begin{array}{l}0.00893 \\
(0.0262)\end{array}$ & $\begin{array}{l}0.00954 \\
(0.0239)\end{array}$ & & $\begin{array}{l}0.0167 \\
(0.0276)\end{array}$ \\
\hline White & $\begin{array}{l}0.0268^{* *} \\
(0.0108)\end{array}$ & $\begin{array}{l}0.0281^{* * *} \\
(0.0107)\end{array}$ & $\begin{array}{l}0.106 \\
(0.130)\end{array}$ & $\begin{array}{l}0.0247^{* *} \\
(0.0116)\end{array}$ \\
\hline Post & $\begin{array}{l}0.0153 \\
(0.0131)\end{array}$ & $\begin{array}{l}0.0127 \\
(0.0137)\end{array}$ & $\begin{array}{l}0.340^{* *} \\
(0.140)\end{array}$ & $\begin{array}{l}0.0163 \\
(0.0158)\end{array}$ \\
\hline Crime & & $\begin{array}{l}-0.0155^{* * *} \\
(0.00544)\end{array}$ & $\begin{array}{l}-0.0152^{* * *} \\
(0.00548)\end{array}$ & $\begin{array}{l}-0.0174^{* * *} \\
(0.00666)\end{array}$ \\
\hline GED & & $\begin{array}{l}-0.00261 \\
(0.00514)\end{array}$ & $\begin{array}{l}-0.00567 \\
(0.00492)\end{array}$ & $\begin{array}{l}-0.00307 \\
(0.00656)\end{array}$ \\
\hline Employment Gap & & $\begin{array}{l}0.000232 \\
(0.00466)\end{array}$ & $\begin{array}{l}0.00131 \\
(0.00456)\end{array}$ & $\begin{array}{l}0.00366 \\
(0.00577)\end{array}$ \\
\hline Constant & $\begin{array}{l}0.0962^{* * *} \\
(0.0199)\end{array}$ & $\begin{array}{l}0.108^{* * *} \\
(0.0267)\end{array}$ & $\begin{array}{l}-0.0101 \\
(0.0256)\end{array}$ & $\begin{array}{l}0.0986^{* * *} \\
(0.0216)\end{array}$ \\
\hline Observations & 14640 & 14640 & 14640 & 11188 \\
\hline$R^{2}$ & 0.002 & 0.027 & 0.193 & 0.003 \\
\hline Chain FE & No & No & Yes & No \\
\hline Post $x$ Chain FE & No & No & Yes & No \\
\hline White $x$ Chain FE & No & No & Yes & No \\
\hline Center FE & Yes & Yes & Yes & Yes \\
\hline Sample & All & All & All & Quad \\
\hline
\end{tabular}

Notes: Standard errors in parenthesis clustered on chain. Dependent variable is whether the application received a callback. The Quad sample indicates the "perfect quad" sample of 11,118 observations where we sent exactly 4 applications, one white/black pair in each period. Fixed effects can include, chain, post $\mathrm{x}$ chain, white $\mathrm{x}$ chain, or center, and are included as indicated. 
Table 5A: Robustness Checks: Triple Difference Specification

\begin{tabular}{|c|c|c|c|c|c|c|c|c|}
\hline & (1) & (2) & (3) & (4) & (5) & (6) & (7) & (8) \\
\hline $\begin{array}{l}\text { Post } x \text { Treated } \\
\text { x White }\end{array}$ & $\begin{array}{l}0.0358^{* *} \\
(0.018)\end{array}$ & $\begin{array}{l}0.0326^{* *} \\
(0.016)\end{array}$ & $\begin{array}{l}0.0328^{* *} \\
(0.017)\end{array}$ & $\begin{array}{l}0.0361^{* * *} \\
(0.018)\end{array}$ & $\begin{array}{l}0.0464 \\
(0.037)\end{array}$ & $\begin{array}{l}0.0266 \\
(0.020)\end{array}$ & $\begin{array}{l}0.0349^{*} \\
(0.018)\end{array}$ & $\begin{array}{l}0.0348^{*} \\
(0.018)\end{array}$ \\
\hline Observations & 14640 & 14640 & 14816 & 14581 & 6401 & 8239 & 14640 & 14640 \\
\hline$R^{2}$ & 0.193 & 0.171 & 0.197 & 0.191 & 0.216 & 0.228 & 0.236 & 0.226 \\
\hline Specification & Main & Interview & Main & Main & Main & Main & $\begin{array}{l}\text { Ungroup } \\
\text { Chain }\end{array}$ & $\begin{array}{l}\text { Chain } x \\
\text { NJ FE }\end{array}$ \\
\hline Sample & All & All & $\begin{array}{l}\text { Add Rev } \\
\text { Compliers }\end{array}$ & $\begin{array}{l}\text { Drop } \\
\text { RA } \\
\text { Errors }\end{array}$ & $\mathrm{NJ}$ & NYC & All & All \\
\hline
\end{tabular}

Notes: Standard errors clustered on chain in parenthesis. Dependent variable is whether the application received a positive call back, except in column (2) where it is whether the application received a specific request for an interview. All regressions include controls for, crime, GED, emp. gap, and fixed effects for center, chain, chain $\mathrm{x}$ white and chain $\mathrm{x}$ post. Column (1) recreates Table 4 Column (3). The remaining columns are each different modifications of this specification. Column (2) uses interview as the dependent variable, Column (3) adds in the reverse compliers, Column (4) drops instances where RA erred and answered a box question they were not required to answer or did not answer one they should have, Column (5) is restricted to only NJ, Column (6) is only NYC, Column (7) uses individual chain fixed effects regardless of size, and Column (8) divides chain fixed effects into NJ and NYC.

Table 5B: Robustness Checks: Triple Difference Specification in Perfect Quad Sample

\begin{tabular}{lllllll}
\hline & $(1)$ & $(2)$ & $(3)$ & $(4)$ & $(5)$ & $(6)$ \\
\hline $\begin{array}{l}\text { Post x Treated } \\
\text { x White }\end{array}$ & $0.0399^{* *}$ & $0.0394^{* *}$ & $0.0351^{*}$ & $0.0387^{*}$ & 0.0500 & 0.0335 \\
& $(0.020)$ & $(0.020)$ & $(0.019)$ & $(0.020)$ & $(0.040)$ & $(0.021)$ \\
\hline Observations & 11188 & 11188 & 11324 & 11128 & 4376 & 6812 \\
$R^{2}$ & 0.003 & 0.004 & 0.003 & 0.003 & 0.007 & 0.003 \\
Specification & Main & Interview & Main & Main & Main & Main \\
Sample & Quad & Quad & Quad + Quad-Drop & Quad NJ & Quad NYC \\
& \multicolumn{7}{c}{$\begin{array}{l}\text { Rev. } \\
\text { Compliers }\end{array}$} \\
& & RA Errors \\
\end{tabular}

Notes: Observations restricted to the "perfect quad" sample of 11,118 observations where we sent exactly 4 applications, one white/black pair in each period. Standard errors clustered on chain in parenthesis. Dependent variable is whether the application received a positive call back, except in column (2) where it is whether the application received a specific request for an interview. All regressions include controls for center FE, crime, GED, emp. gap. Panel A Column (1) recreates Table 4 Column (4). The remaining columns are each different modifications of this specification. Column (2) uses interview as the dependent variable, Column (3) adds in the reverse compliers, Column (4) drops instances where RA erred and answered a box question they were not required to answer or did not answer one they should have, Column (5) is restricted to only NJ, Column (6) is only NYC. 


\section{Appendix}

\section{A1. Applicant Profile Details}

Applicant profiles consist of all information that our RAs might need in order to fill out a given job application. In addition to the characteristics we randomly varied, it was necessary to include other types of information such as previous job titles and descriptions, home addresses, names of high schools, references, and e-mail addresses. We wanted to keep these additional characteristics as similar as possible while still introducing slight (random) variation so as not to arouse employer suspicion.

(1) Work history: All job applicants have about 3.5 years of work experience: about 2 years as crew members at fast-food chains or convenience stores and about 1.5 years in manual labor jobs such as home improvement, landscaping, or moving. The fast-food chains or convenience stores were a set real companies that we were not applying to. Each applicant was randomly assigned a company from that list of fast-food chains or convenience stores. They were given crew member or team member positions and assigned relatively generic job duties meant to imply they held basic entry-level cashier-type positions at the establishments.

The manual labor jobs were randomly assigned to be in landscaping, paving, moving, home improvement, or lawn care and were not given real company names. Company names were made up but based on names standard to the industries involved (e.g., A1 Best Landscaping, [Reference Last Name] Contracting LLC, or Newark Home Improvement Inc.). Applicants were similarly assigned generic job duties meant to imply entry-level, unskilled crew-member or assistant positions in the fictitious companies.

All applicants are unemployed at the time of the job application, having ended their most recent job 2 or 3 months before the application is submitted. Descriptions of previous job duties and reasons for leaving jobs varied slightly. Applicants with employment gaps have 11 to 13 months of unemployment between the two jobs; those without employment gaps have only 0 - to 2-month gaps.

(2) Address and center city: Because it is likely that employers would be concerned about employees being able to travel to work, we wanted applicants to live near the jobs they 
apply to. As described in the text, to achieve that, we chose 40 geographically distributed cities or towns in New Jersey and 44 in New York City to serve as centers where the applicants' addresses would be located; each center then served as the base for applications to jobs located nearby. To choose the centers, we first narrowed down the entire list of New Jersey cities and towns as well as community districts in New York City to those that were at least $6 \%$ black, were at least $20 \%$ white, and had median annual incomes less than $\$ 100,000$. We then used an optimization tool in the ArcGIS software package to select among those possibilities the 40 centers that would minimize distance to jobs; in New Jersey this was based on the distribution of postings then found (in January 2015) on snagajob.com, and in New York City it was based on the locations of employers that we located in the BusinessUSA database. In New Jersey, we assigned every municipality in the state to its nearest center, excluding only a few small towns that were more than 20 miles from any center. In New York City, we minimized distances subject to a constraint of equal distribution of chains across centers - for example, all chains with 44 or fewer locations were distributed such that no more than one location was assigned to each center, while a chain with 45 to 88 locations would be distributed with one to two locations per center, and so forth.

Within each center, eight qualifying addresses were located within census blocks that were at least $10 \%$ black and $20 \%$ white and that had a median annual income less than $\$ 100,000$. All addresses came from different streets, and we used Google Street View to ensure that the choices were appropriate residential or mixed-use blocks and that they did not notably differ from one another. Addresses were then slightly changed so as not to represent real addresses, and they were then randomly assigned to applicants.

(3) High school or GED program: For diploma earners, high schools for the New Jersey applicants were chosen to be in New Jersey cities or towns at least 30 miles away from the center where the applicant would apply from to reduce the probability that the high school could send any unobservable signals to the employer. High schools for the New York City study were divided equally between New Jersey and upstate New York schools, since similar geographic separation could not be achieved within the city. The high schools used were all at least $10 \%$ black, are at least $20 \%$ white, have at least 25,000 people, and do not have median incomes more than $\$ 100,000$. In addition, the high schools do not have median 
test scores above the 90th or below the 10th percentile in the state. Applicants with GEDs were randomly assigned descriptions and names of New Jersey or New York GED training programs.

(4) References: Two fictitious references with phone numbers were created, representing the applicant's supervisors for each of two previous jobs. To complement and strengthen the racial signal provided by our applicant names, the previous supervisor from the manual labor job was also given a racially distinctive name suggesting the same race as the applicant. The previous supervisor of the retail or restaurant job was given a race-neutral name. However, no employers ever called the phone numbers that we purchased and provided for the references, suggesting that little attention was likely paid to them.

(5) Phone number: Each applicant was assigned a phone number based on center, race, criminal history, and time period. (Thus, each center has at least four potential phone numbers during each phase of the study; in New York City, because we were sending a larger number of distinct applications per center, we bought two numbers for each combination of characteristics and varied them randomly.) The result of that division is that no store received two applications using the same phone number. That method also helps us identify which application a voice mail belongs to, because hiring managers would not always leave all pertinent information on the voice mail. The information left, combined with the phone number being called, was sufficient to uniquely assign responses to applications. We purchased these phone numbers from www.callfire.com, which enabled us to create voicemails for our applicants using one of several available robotic voices. The wording and voice on the outgoing voice mail greeting were randomized across several options and designed to sound like a generic cell phone voice mail greeting for someone who has not recorded a personalized one.

(6) E-mail address: A unique e-mail address was created for each applicant, with the format randomly varied. All e-mail addresses were created with the same domain, and the format always included the applicant's first and last names but could also include numbers, a middle initial, periods, or underscores so as to differentiate the format across applicants to the same store. 
(7) Criminal record: Applicants with felony convictions were randomly assigned either a property crime or a drug crime. Within those two categories, several potential crimes were chosen - all of them meant to imply similar levels of seriousness. In addition, many applications with the box ask the applicant to "Please explain." For that, specific language was given as part of the profiles, with sentences randomly generated to indicate when the crime occurred, a potential expression of remorse, and a potential expression of desire to discuss the matter further in person.

We randomly generated each profile using the Resume Randomizer program of Lahey and Beasley (2009). Applicant pairs were always of opposite race, and were otherwise created so that the details of the aforementioned characteristics were randomly varied among the pair. For example, both members of the pair could have high school diplomas, but never from the same high school or the same town; no two applicants in the same pair had the same address; none worked for the exact same former employers; if both had a criminal record, it did not involve the same criminal charge, and so forth. For examples of profiles, which are several pages in length, please e-mail the authors. 


\section{A2. Names Used}

Table A2.1: White and Black Names Used for Applicants

\begin{tabular}{|c|c|c|c|c|c|c|c|}
\hline \multicolumn{4}{|c|}{ White Names } & \multicolumn{4}{|c|}{ Black Names } \\
\hline First & $\%$ White & Last & $\%$ White & First & $\%$ Black & Last & $\%$ Black \\
\hline SCOTT & 88.87 & WEBER & 94.37 & TYREE & 97.94 & PIERRE & 97.78 \\
\hline THOMAS & 86.92 & ESPOSITO & 93.30 & TERRELL & 96.23 & WASHINGTON & 90.28 \\
\hline CODY & 86.71 & SCHMIDT & 92.63 & DAQUAN & 96.04 & ALSTON & 88.96 \\
\hline RYAN & 85.37 & BRENNAN & 92.45 & JAQUAN & 95.03 & BYRD & 85.50 \\
\hline NICHOLAS & 84.99 & MEYER & 92.27 & DARNELL & 93.43 & INGRAM & 78.63 \\
\hline DYLAN & 84.70 & KANE & 91.75 & JAMAL & 91.36 & JACKSON & 76.32 \\
\hline MATTHEW & 83.97 & HOFFMAN & 91.38 & MARQUIS & 91.36 & BANKS & 75.68 \\
\hline JACOB & 83.37 & RYAN & 89.98 & JERMAINE & 89.45 & FIELDS & 74.83 \\
\hline KYLE & 82.93 & WAGNER & 89.96 & DENZEL & 89.27 & BRYANT & 74.49 \\
\hline TYLER & 82.82 & HANSEN & 89.60 & DWAYNE & 88.89 & WILLIAMS & 74.22 \\
\hline SEAN & 82.41 & SNYDER & 88.84 & REGINALD & 88.41 & SIMMONS & 72.45 \\
\hline DOUGLAS & 81.93 & ROMANO & 88.84 & TYRONE & 86.75 & CHARLES & 72.33 \\
\hline SHANE & 81.11 & O'NEILL & 88.72 & MALCOLM & 86.06 & HAWKINS & 70.81 \\
\hline JOHN & 80.36 & RUSSO & 88.67 & DARRYL & 84.78 & ROBINSON & 70.70 \\
\hline \multirow[t]{4}{*}{ STEPHEN } & 80.12 & FOX & 86.43 & TERRANCE & 84.12 & JENKINS & 70.50 \\
\hline & & SWEENEY & 86.03 & MAURICE & 82.47 & FRANKLIN & 70.45 \\
\hline & & SULLIVAN & 85.08 & ISAIAH & 74.06 & JOSEPH & 70.42 \\
\hline & & & & ELIJAH & 72.35 & & \\
\hline
\end{tabular}

Notes: The \%race columns indicate the percentage of male babies born in NJ between 1989 and 1997 with that first or last name that were of that race (i.e. $88.87 \%$ of male babies with the first name Scott are White). 


\section{A3. Robustness checks for main effects of Race and Crime}

Table A3.1: Robustness Checks on Main Effect of White

\begin{tabular}{llllll}
\hline & $(1)$ & $(2)$ & $(3)$ & $(4)$ & $(5)$ \\
\hline White & $0.0239^{* * *}$ & $0.0136^{* * *}$ & $0.0242^{* * *}$ & $0.0454^{* * *}$ & 0.0073 \\
& $(0.0054)$ & $(0.0045)$ & $(0.0054)$ & $(0.0097)$ & $(0.0050)$ \\
\hline Observations & 14640 & 14640 & 14640 & 6401 & 8239 \\
Specification & Main & Interview & Ungroup & Main & Main \\
& & & Chain FE & NJ-All & NYC-All \\
Sample & All & All & All & N
\end{tabular}

Notes: Dependent variable is whether the application received a callback. Standard errors clustered on chain in parentheses. Column (1) reproduces the White coefficient from Column 2 of Table 2, and the remaining columns show the White coefficient from different specifications. Column (2) uses interview as the dependent variable rather callback. Column (3) uses ungrouped chain FE rather than grouped. Columns (4) and (5) separate the sample in the NJ sample and the NYC sample.

Table A3.2: Robustness Checks on Main Effect of Crime in the Box Sample Only

\begin{tabular}{llllll}
\hline & $(1)$ & $(2)$ & $(3)$ & $(4)$ & $(5)$ \\
\hline Crime & $-0.0520^{* * *}$ & $-0.0353^{* * *}$ & $-0.0522^{* * *}$ & $-0.0535^{* *}$ & $-0.0513^{* * *}$ \\
& $(0.0121)$ & $(0.0062)$ & $(0.0123)$ & $(0.0220)$ & $(0.0160)$ \\
\hline Observations & 2918 & 2918 & 2918 & 1156 & 1762 \\
Specification & Main & Interview & Ungroup & Main & Main \\
& & & Chain FE & & \\
Sample & All & All & All & NJ-All & NYC-All \\
\hline
\end{tabular}

Notes: All regressions are conditional on the application having the box. Dependent variable is whether the application received a callback. Standard errors clustered on chain in parentheses. Column (1) reproduces the Crime coefficient from Column 4 of Table 2, and the remaining columns show the Crime coefficient from different specifications. Column (2) uses interview as the dependent variable rather callback. Column (3) uses ungrouped chain FE rather than grouped. Columns (4) and (5) separate the sample in the NJ sample and the NYC sample. 


\section{A4. Analysis Tables for NJ Only}

This appendix recreates Figures 1 and 2 as well as Table 1a and 1b, Table 2 and 4 for only NJ only.

Figure A4.1: Callback Rates by Race, Crime, and Box: Pre-Period NJ Applications Only

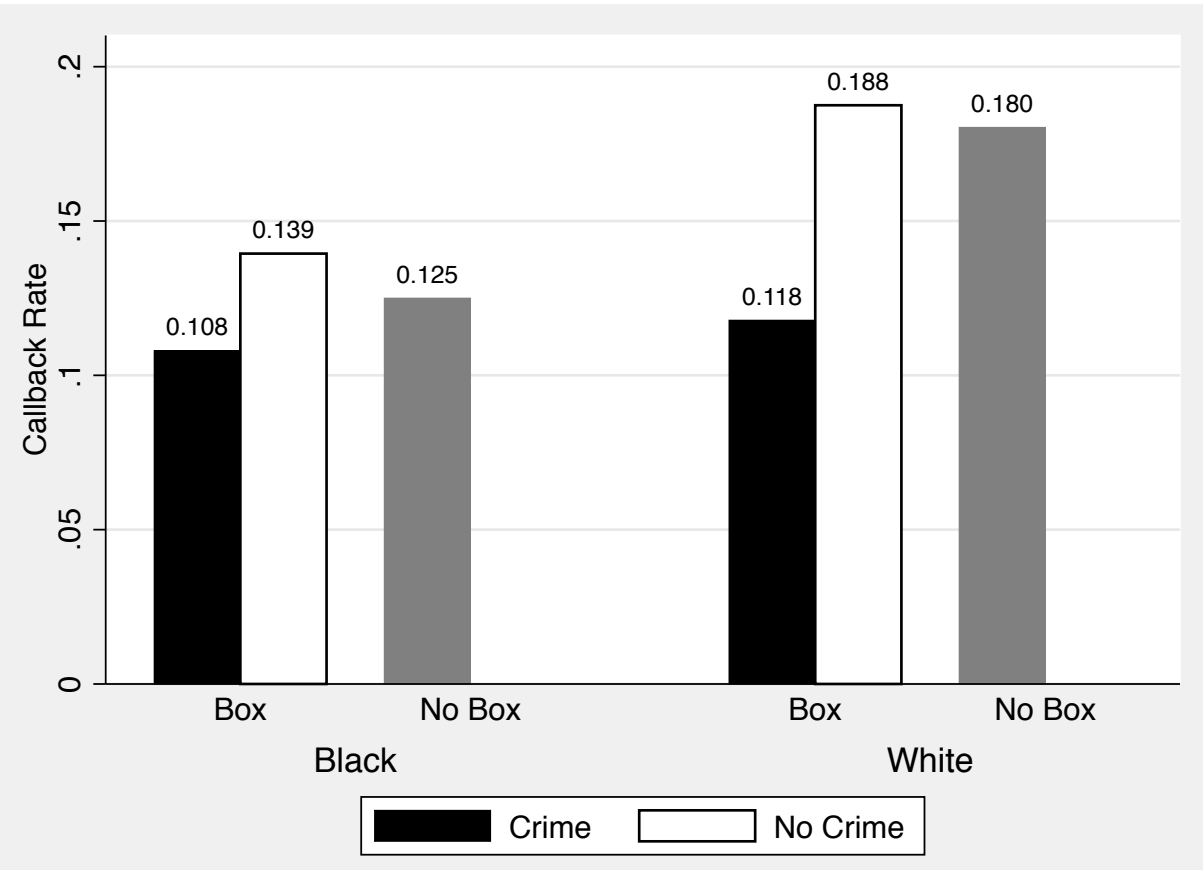

Notes: Limited to only NJ applications. This figure compares callback rates within the pre-period before Ban the Box goes into effect, comparing applications with the box (application which ask about criminal records) and those without (applications that do not ask about criminal records). A callback is a personalized phone call or e-mail to the applicant requesting follow-up contact or an interview. 
Figure A4.2: Callback Rates by Race, Criminal Record, and Period: NJ Treated Only

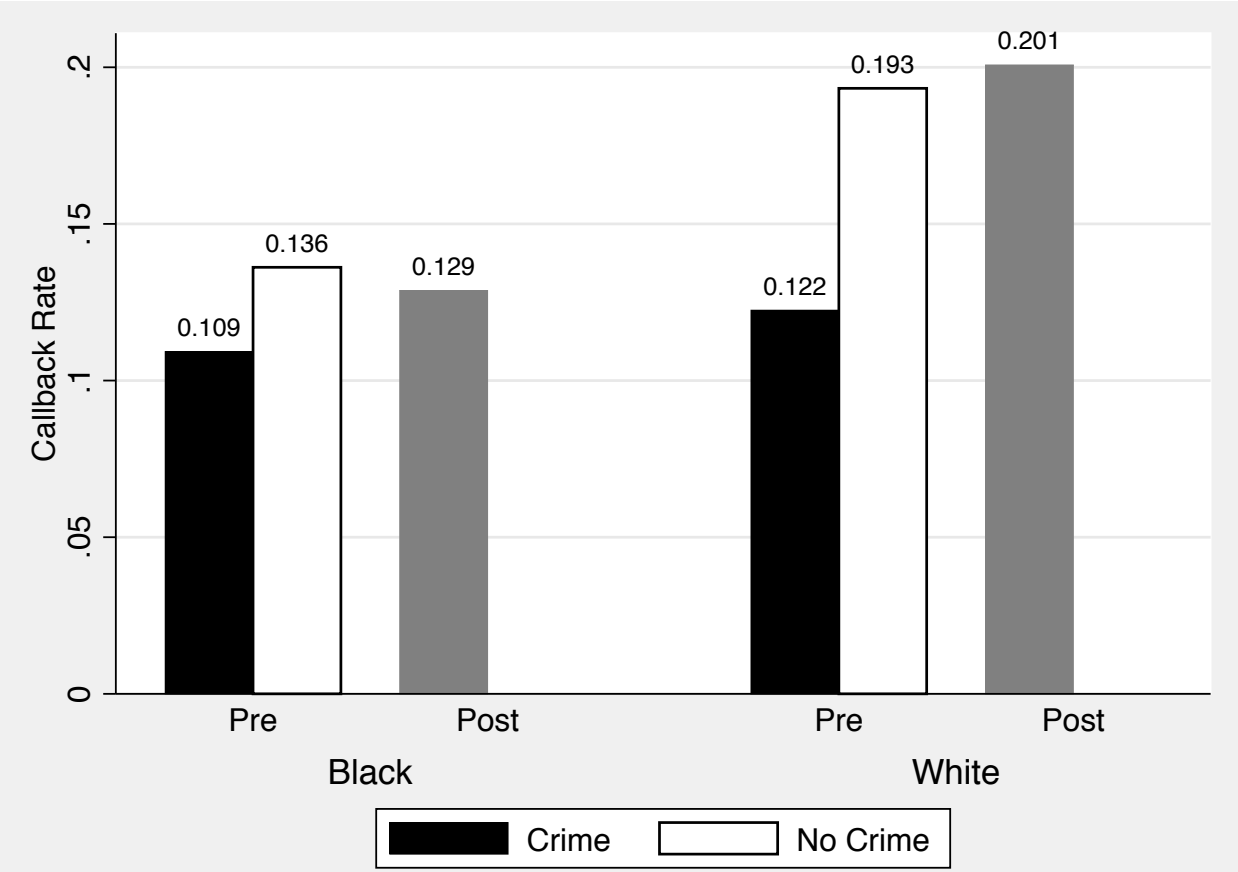

Notes: Limited to only NJ applications. This figure compares callback rates within treated companies, i.e. those companies that asked the criminal record question in the pre-period, before and after Ban the Box goes into effect. A callback is a personalized phone call or e-mail to the applicant requesting follow-up contact or an interview. 
Table A4.1a: Means of Applicant and Application Characteristics and Callback Rates by Period, NJ Only

\begin{tabular}{llll}
\hline & Pre-Period & Post-Period & Combined \\
\hline Characteristics: & & & \\
White & 0.507 & 0.495 & 0.500 \\
Crime & 0.498 & 0.504 & 0.501 \\
GED & 0.506 & 0.513 & 0.510 \\
Employment Gap & 0.503 & 0.504 & 0.504 \\
Application has Box & 0.362 & 0.034 & 0.181 \\
& & & \\
Results: & & & \\
Callback Rate & 0.147 & 0.146 & 0.147 \\
Interview Req & 0.081 & 0.076 & 0.078 \\
& & & \\
Callback Rate & by & & \\
Characteristics: & & & \\
Black & 0.125 & 0.124 & 0.124 \\
White & 0.170 & 0.170 & 0.170 \\
GED & 0.139 & 0.143 & 0.142 \\
HSD & 0.156 & 0.150 & 0.152 \\
Emp Gap & 0.145 & 0.149 & 0.147 \\
No Emp Gap & 0.150 & 0.144 & 0.146 \\
\hline Observations & 2864 & 3537 & 6401 \\
\hline
\end{tabular}

Notes: Sample limited to NJ applications. Callback implies application received a personalized positive response from the employer (either via phone or e-mail). Interview request means the positive response specifically mentioned an interview. Application has box means that the application asked about criminal records. Employment (emp) gap is a 11-13 month employment gap in work history, no emp gap is a 0-2 month gap.

Table A4.1b: Callback Rates by Crime Status for Stores with the Box in the Pre-Period, NJ Only

\begin{tabular}{llllll}
\hline & No Crime & Crime & Property & Drug & Combined \\
\hline Callback Rate & 0.164 & 0.113 & 0.102 & 0.127 & 0.138 \\
Callback Black & 0.139 & 0.108 & 0.087 & 0.139 & 0.124 \\
Callback White & 0.188 & 0.118 & 0.118 & 0.118 & 0.151 \\
\hline Observations & 507 & 530 & 293 & 237 & 1037
\end{tabular}

Notes: Sample restricted to pre-period applications in NJ where the application asked about criminal records. Callback implies application received a personalized positive response from the employer. 
Table A4.2: Effects of Applicant Characteristics on Callback Rates NJ ONLY

\begin{tabular}{|c|c|c|c|c|c|c|}
\hline & (1) & (2) & (3) & (4) & (5) & (6) \\
\hline White & $\begin{array}{l}0.0466 * * * \\
(0.0100)\end{array}$ & $\begin{array}{l}0.0454 * * * \\
(0.0097)\end{array}$ & $\begin{array}{l}0.0500 * * * \\
(0.0116)\end{array}$ & $\begin{array}{l}0.0260 \\
(0.0213)\end{array}$ & $\begin{array}{l}0.0251 \\
(0.0210)\end{array}$ & $\begin{array}{l}0.0515 \\
(0.0360)\end{array}$ \\
\hline Crime & $\begin{array}{l}-0.0157 * * \\
(0.0070)\end{array}$ & $\begin{array}{l}-0.0153 * * \\
(0.0071)\end{array}$ & & $\begin{array}{l}-0.0535 * * \\
(0.0220)\end{array}$ & & $\begin{array}{l}-0.0280 \\
(0.0326)\end{array}$ \\
\hline GED & $\begin{array}{l}-0.0120 \\
(0.0089)\end{array}$ & $\begin{array}{l}-0.0161 * * \\
(0.0078)\end{array}$ & $\begin{array}{l}-0.0210^{* *} \\
(0.0087)\end{array}$ & $\begin{array}{l}-0.0026 \\
(0.0285)\end{array}$ & $\begin{array}{l}-0.0016 \\
(0.0281)\end{array}$ & $\begin{array}{l}-0.0000 \\
(0.0273)\end{array}$ \\
\hline $\begin{array}{l}\text { Employment } \\
\text { Gap }\end{array}$ & $\begin{array}{l}0.0008 \\
(0.0073)\end{array}$ & $\begin{array}{l}0.0011 \\
(0.0071)\end{array}$ & $\begin{array}{l}0.0024 \\
(0.0080)\end{array}$ & $\begin{array}{l}-0.0065 \\
(0.0123)\end{array}$ & $\begin{array}{l}-0.0057 \\
(0.0123)\end{array}$ & $\begin{array}{l}-0.0062 \\
(0.0125)\end{array}$ \\
\hline Pre-Period & & $\begin{array}{l}-0.0034 \\
(0.0138)\end{array}$ & & & & \\
\hline Drug Crime & & & & & $\begin{array}{l}-0.0423 \\
(0.0305)\end{array}$ & \\
\hline Property Crime & & & & & $\begin{array}{l}-0.0626 * * \\
(0.0250)\end{array}$ & \\
\hline White $\mathrm{x}$ Crime & & & & & & $\begin{array}{l}-0.0499 \\
(0.0368)\end{array}$ \\
\hline Constant & $\begin{array}{l}0.1372 * * * \\
(0.0192)\end{array}$ & $\begin{array}{l}0.0392 \\
(0.0380)\end{array}$ & $\begin{array}{l}0.0333 \\
(0.0368)\end{array}$ & $\begin{array}{l}0.0137 \\
(0.0958)\end{array}$ & $\begin{array}{l}0.0128 \\
(0.0971)\end{array}$ & $\begin{array}{l}0.0021 \\
(0.1002)\end{array}$ \\
\hline Observations & 6401 & 6401 & 5245 & 1156 & 1156 & 1156 \\
\hline Sample & All & All & Non-Box & Box & Box & Box \\
\hline Chain FE & No & Yes & Yes & Yes & Yes & Yes \\
\hline Center FE & No & Yes & Yes & Yes & Yes & Yes \\
\hline
\end{tabular}

Notes: This table recreates Table 2 for NJ only. Dependent variable is whether the application received a callback. Standard errors clustered on chain in parentheses. The non-box sample includes only applications that did not ask about criminal history; the box sample includes only those applications that asked about criminal records. Chain and center fixed effects are included in Columns (2) - (6) as indicated. White is as compared to black applicants, crime is as compared to no-crime, GED is as compared to a HS Diploma and Emp. Gap is a 11-13 month gap in work history as compared to a 0-2 month gap. 
Table A4.3: Effects of Ban the Box on Racial Discrimination, Triple Difference Specification NJ ONLY

\begin{tabular}{|c|c|c|c|c|}
\hline & (1) & (2) & (3) & (4) \\
\hline Post $x$ Treated $x$ White & $\begin{array}{l}0.0523 \\
(0.0380)\end{array}$ & $\begin{array}{l}0.0587 \\
(0.0381)\end{array}$ & $\begin{array}{l}0.0464 \\
(0.0371)\end{array}$ & $\begin{array}{l}0.0500 \\
(0.0395)\end{array}$ \\
\hline Post $\mathrm{x}$ White & $\begin{array}{l}-0.0158 \\
(0.0234)\end{array}$ & $\begin{array}{l}-0.0184 \\
(0.0232)\end{array}$ & $\begin{array}{l}-0.0106 \\
(0.0227)\end{array}$ & $\begin{array}{l}0.00152 \\
(0.0289)\end{array}$ \\
\hline Post $x$ Treated & $\begin{array}{l}0.0113 \\
(0.0280)\end{array}$ & $\begin{array}{l}0.00765 \\
(0.0273)\end{array}$ & & $\begin{array}{l}0.00413 \\
(0.0373)\end{array}$ \\
\hline White $\mathrm{x}$ Treated & $\begin{array}{l}-0.0144 \\
(0.0307)\end{array}$ & $\begin{array}{l}-0.0195 \\
(0.0307)\end{array}$ & & $\begin{array}{l}-0.00442 \\
(0.0314)\end{array}$ \\
\hline Treated & $\begin{array}{l}-0.00383 \\
(0.0335)\end{array}$ & $\begin{array}{l}-0.00290 \\
(0.0325)\end{array}$ & & $\begin{array}{l}0.00344 \\
(0.0396)\end{array}$ \\
\hline White & $\begin{array}{l}0.0498^{* *} \\
(0.0206)\end{array}$ & $\begin{array}{l}0.0536^{* *} \\
(0.0205)\end{array}$ & $\begin{array}{l}0.0188 \\
(0.0348)\end{array}$ & $\begin{array}{l}0.0405^{*} \\
(0.0204)\end{array}$ \\
\hline Post & $\begin{array}{l}-0.00447 \\
(0.0214)\end{array}$ & $\begin{array}{l}-0.000530 \\
(0.0213)\end{array}$ & $\begin{array}{l}1.019^{* * *} \\
(0.0348)\end{array}$ & $\begin{array}{l}-0.00828 \\
(0.0286)\end{array}$ \\
\hline Crime & & $\begin{array}{l}-0.0158^{* *} \\
(0.00678)\end{array}$ & $\begin{array}{l}-0.0151^{* *} \\
(0.00709)\end{array}$ & $\begin{array}{l}-0.0165^{* *} \\
(0.00788)\end{array}$ \\
\hline GED & & $\begin{array}{l}-0.0126 \\
(0.00846)\end{array}$ & $\begin{array}{l}-0.0174^{* *} \\
(0.00758)\end{array}$ & $\begin{array}{l}-0.0133 \\
(0.0123)\end{array}$ \\
\hline Employment Gap & & $\begin{array}{l}0.00108 \\
(0.00718)\end{array}$ & $\begin{array}{l}0.00146 \\
(0.00667)\end{array}$ & $\begin{array}{l}0.00544 \\
(0.0100)\end{array}$ \\
\hline Constant & $\begin{array}{l}0.126^{* * *} \\
(0.0277)\end{array}$ & $\begin{array}{l}0.183^{* * *} \\
(0.0478)\end{array}$ & $\begin{array}{l}0.0489 \\
(0.0360)\end{array}$ & $\begin{array}{l}0.138^{* * *} \\
(0.0354)\end{array}$ \\
\hline Observations & 6401 & 6401 & 6401 & 4376 \\
\hline$R^{2}$ & 0.005 & 0.031 & 0.216 & 0.007 \\
\hline Chain FE & No & No & Yes & No \\
\hline Post $x$ Chain FE & No & No & Yes & No \\
\hline White $x$ Chain FE & No & No & Yes & No \\
\hline Center FE & Yes & Yes & Yes & Yes \\
\hline Sample & All & All & All & Quad \\
\hline
\end{tabular}

Notes: This table recreates Table 4 for NJ only. Standard errors in parenthesis clustered on chain. Dependent variable is whether the application received a callback. The Quad sample indicates the "perfect quad" sample of observations where we sent exactly 4 applications, one white/black pair in each period. Fixed effects can include, chain, post $\mathrm{x}$ chain, white $\mathrm{x}$ chain, or center, and are included as indicated. 


\section{A5. Analysis Tables for NYC Only}

This appendix recreates Figures 1 and 2 as well as Table 1a and 1b, Table 2 and 4 for only NJ only.

Figure A5.1: Callback Rates by Race, Crime, and Box: Pre-Period NYC Applications Only

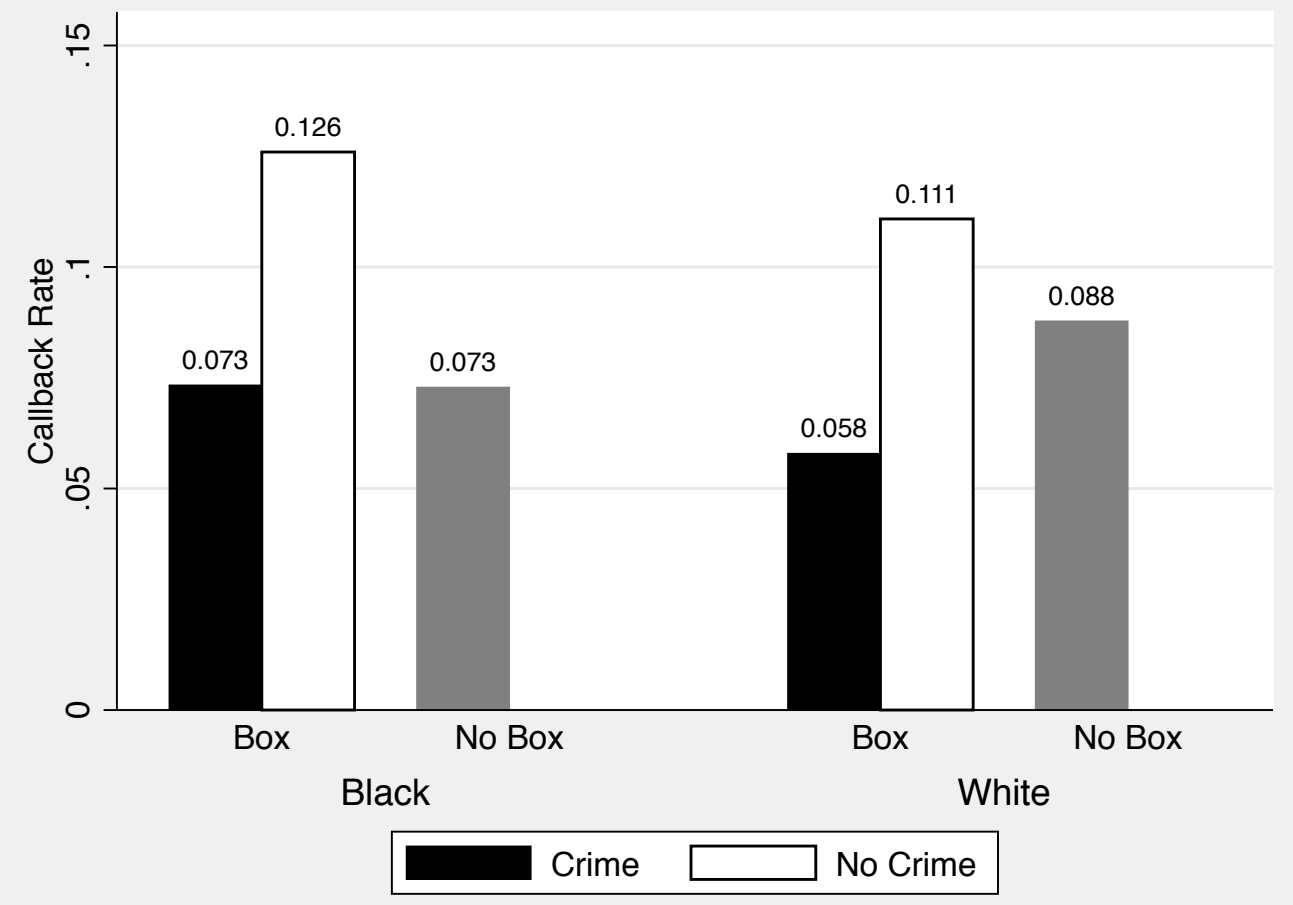

Notes: Limited to only NYC applications. This figure compares callback rates within the pre-period before Ban the Box goes into effect, comparing applications with the box (application which ask about criminal records) and those without (applications that do not ask about criminal records). A callback is a personalized phone call or e-mail to the applicant requesting follow-up contact or an interview. 
Figure A5.2: Callback Rates by Race, Criminal Record, and Period: NYC Treated Only

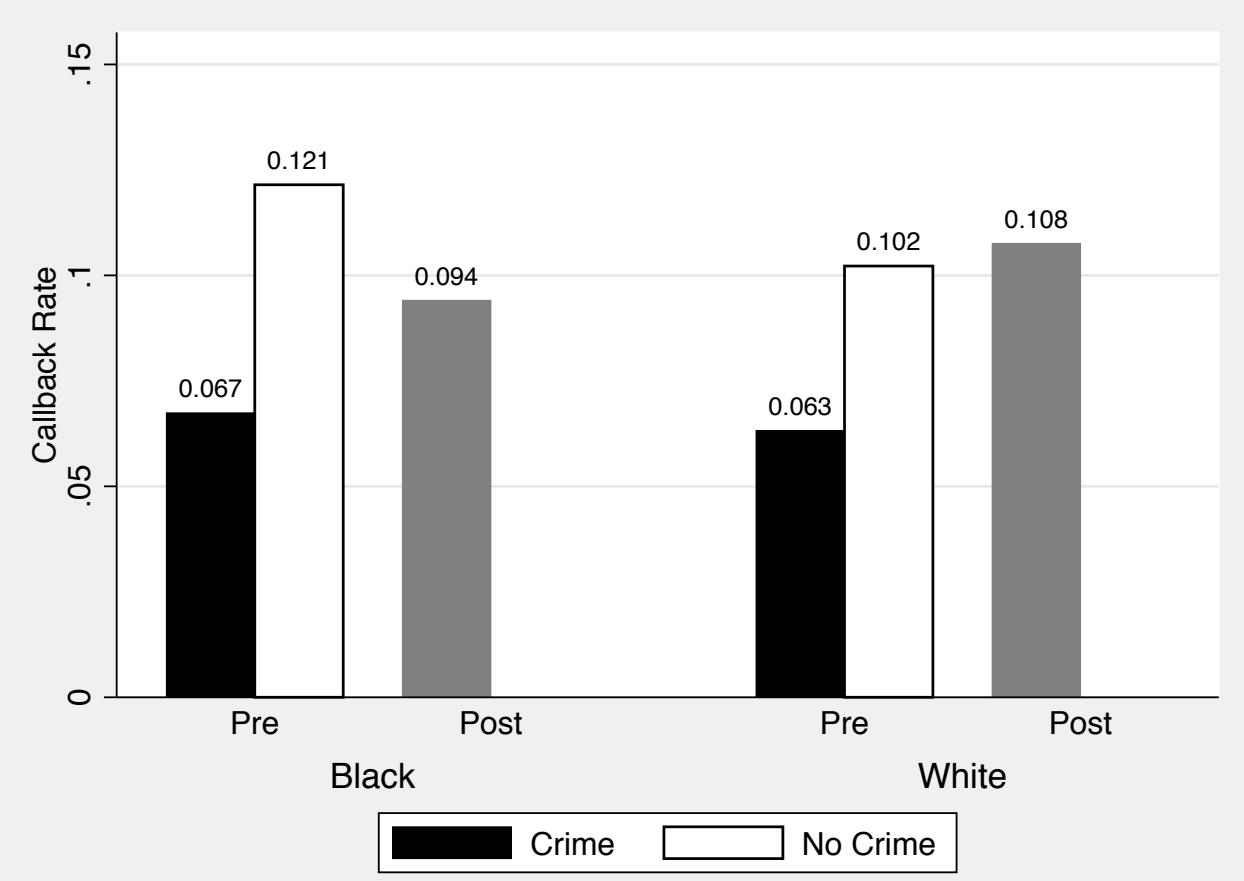

Notes: Limited to only NYC applications. This figure compares callback rates within treated companies, i.e. those companies that asked the criminal record question in the pre-period, before and after Ban the Box goes into effect. A callback is a personalized phone call or e-mail to the applicant requesting follow-up contact or an interview. 
Table A5.1a: Means of Applicant and Application Characteristics and Callback Rates by Period, NYC Only

\begin{tabular}{llll}
\hline & Pre-Period & Post-Period & Combined \\
\hline Characteristics: & & & \\
White & 0.500 & 0.499 & 0.499 \\
Crime & 0.496 & 0.521 & 0.508 \\
GED & 0.492 & 0.492 & 0.492 \\
Employment Gap & 0.485 & 0.505 & 0.494 \\
Application has Box & 0.369 & 0.037 & 0.214 \\
& & & \\
Results: & & & \\
Callback Rate & 0.085 & 0.105 & 0.094 \\
Interview Req & 0.046 & 0.059 & 0.052 \\
& & & \\
Callback Rate & by & & \\
Characteristics: & & & \\
Black & 0.083 & 0.099 & 0.090 \\
White & 0.087 & 0.110 & 0.098 \\
GED & 0.083 & 0.112 & 0.097 \\
HSD & 0.086 & 0.098 & 0.092 \\
Emp Gap & 0.086 & 0.104 & 0.095 \\
No Emp Gap & 0.084 & 0.105 & 0.094 \\
\hline Observations & 4382 & 3857 & 8239 \\
\hline
\end{tabular}

Notes: Sample limited to NYC applications. Callback implies application received a personalized positive response from the employer (either via phone or e-mail). Interview request means the positive response specifically mentioned an interview. Application has box means that the application asked about criminal records. Employment (emp) gap is a 11-13 month employment gap in work history, no emp gap is a 0-2 month gap.

Table A5.1b: Callback Rates by Crime Status for Stores with the Box in the Pre-Period, NYC Only

\begin{tabular}{llllll}
\hline & No Crime & Crime & Property & Drug & Combined \\
\hline Callback Rate & 0.118 & 0.066 & 0.071 & 0.061 & 0.092 \\
Callback Black & 0.126 & 0.073 & 0.093 & 0.052 & 0.099 \\
Callback White & 0.111 & 0.058 & 0.046 & 0.069 & 0.085 \\
\hline Observations & 812 & 806 & 410 & 396 & 1618 \\
\hline
\end{tabular}

Notes: Sample restricted to pre-period applications in NYC where the application asked about criminal records. Callback implies application received a personalized positive response from the employer. 
Table A5.2: Effects of Applicant Characteristics on Callback Rates: NYC Only

\begin{tabular}{|c|c|c|c|c|c|c|}
\hline & (1) & (2) & (3) & (4) & (5) & (6) \\
\hline White & $\begin{array}{l}0.0073 \\
(0.0050)\end{array}$ & $\begin{array}{l}0.0073 \\
(0.0050)\end{array}$ & $\begin{array}{l}0.0139 * * \\
(0.0060)\end{array}$ & $\begin{array}{l}-0.0182 * * \\
(0.0087)\end{array}$ & $\begin{array}{l}-0.0179^{* *} \\
(0.0087)\end{array}$ & $\begin{array}{l}-0.0239 \\
(0.0146)\end{array}$ \\
\hline Crime & $\begin{array}{l}-0.0168 * * \\
(0.0082)\end{array}$ & $\begin{array}{c}-0.0137^{*} \\
(0.0079)\end{array}$ & & $\begin{array}{l}-0.0513^{* * *} \\
(0.0160)\end{array}$ & & $\begin{array}{l}-0.0571 * * * \\
(0.0184)\end{array}$ \\
\hline GED & $\begin{array}{l}0.0049 \\
(0.0064)\end{array}$ & $\begin{array}{l}0.0044 \\
(0.0059)\end{array}$ & $\begin{array}{l}0.0018 \\
(0.0066)\end{array}$ & $\begin{array}{l}0.0141 \\
(0.0105)\end{array}$ & $\begin{array}{l}0.0136 \\
(0.0104)\end{array}$ & $\begin{array}{l}0.0143 \\
(0.0104)\end{array}$ \\
\hline $\begin{array}{l}\text { Employment } \\
\text { Gap }\end{array}$ & $\begin{array}{l}0.0007 \\
(0.0057)\end{array}$ & $\begin{array}{l}0.0012 \\
(0.0055)\end{array}$ & $\begin{array}{l}-0.0033 \\
(0.0055)\end{array}$ & $\begin{array}{l}0.0213^{*} \\
(0.0117)\end{array}$ & $\begin{array}{l}0.0214^{*} \\
(0.0118)\end{array}$ & $\begin{array}{l}0.0215^{*} \\
(0.0117)\end{array}$ \\
\hline Pre-Period & & $\begin{array}{l}-0.0238 \\
(0.0169)\end{array}$ & & & & \\
\hline Drug Crime & & & & & $\begin{array}{l}-0.0577 * * * \\
(0.0170)\end{array}$ & \\
\hline Property Crime & & & & & $\begin{array}{l}-0.0453^{* * *} \\
(0.0164)\end{array}$ & \\
\hline White $\mathrm{x}$ Crime & & & & & & $\begin{array}{l}0.0115 \\
(0.0192)\end{array}$ \\
\hline Constant & $\begin{array}{l}0.0961 * * * \\
(0.0176)\end{array}$ & $\begin{array}{l}0.0192 \\
(0.0242)\end{array}$ & $\begin{array}{l}0.0168 \\
(0.0277)\end{array}$ & $\begin{array}{l}0.0296 \\
(0.0575)\end{array}$ & $\begin{array}{l}0.0293 \\
(0.0572)\end{array}$ & $\begin{array}{l}0.0329 \\
(0.0567)\end{array}$ \\
\hline Observations & 8239 & 8239 & 6477 & 1762 & 1762 & 1762 \\
\hline Sample & All & All & Non-Box & Box & Box & Box \\
\hline Chain FE & No & Yes & Yes & Yes & Yes & Yes \\
\hline Center FE & No & Yes & Yes & Yes & Yes & Yes \\
\hline
\end{tabular}

Notes: This table recreates Table 2 for NYC only. Dependent variable is whether the application received a callback. Standard errors clustered on chain in parentheses. The non-box sample includes only applications that did not ask about criminal history; the box sample includes only those applications that asked about criminal records. Chain and center fixed effects are included in Columns (2) - (6) as indicated. White is as compared to black applicants, crime is as compared to no-crime, GED is as compared to a HS Diploma and Emp. Gap is a 11-13 month gap in work history as compared to a 0-2 month gap. 
Table A5.3: Effects of BTB on Racial Discrimination, Triple Difference Analysis: NYC ONLY

\begin{tabular}{|c|c|c|c|c|}
\hline & (1) & (2) & (3) & (4) \\
\hline Post $x$ Treated $x$ White & $\begin{array}{l}0.0267 \\
(0.0196)\end{array}$ & $\begin{array}{l}0.0275 \\
(0.0198)\end{array}$ & $\begin{array}{l}0.0266 \\
(0.0203)\end{array}$ & $\begin{array}{l}0.0335 \\
(0.0212)\end{array}$ \\
\hline Post x White & $\begin{array}{l}-0.00191 \\
(0.0112)\end{array}$ & $\begin{array}{l}-0.00165 \\
(0.0112)\end{array}$ & $\begin{array}{l}-0.00402 \\
(0.0113)\end{array}$ & $\begin{array}{l}-0.00380 \\
(0.0103)\end{array}$ \\
\hline Post $x$ Treated & $\begin{array}{l}-0.0253 \\
(0.0344)\end{array}$ & $\begin{array}{l}-0.0268 \\
(0.0342)\end{array}$ & & $\begin{array}{l}-0.0353 \\
(0.0360)\end{array}$ \\
\hline White $\mathrm{x}$ Treated & $\begin{array}{l}-0.0229^{*} \\
(0.0119)\end{array}$ & $\begin{array}{l}-0.0228^{*} \\
(0.0118)\end{array}$ & & $\begin{array}{l}-0.0244^{*} \\
(0.0134)\end{array}$ \\
\hline Treated & $\begin{array}{l}0.0174 \\
(0.0289)\end{array}$ & $\begin{array}{l}0.0173 \\
(0.0283)\end{array}$ & & $\begin{array}{l}0.0265 \\
(0.0292)\end{array}$ \\
\hline White & $\begin{array}{l}0.0116 \\
(0.00839)\end{array}$ & $\begin{array}{l}0.0112 \\
(0.00832)\end{array}$ & $\begin{array}{l}0.240^{* * *} \\
(0.0542)\end{array}$ & $\begin{array}{l}0.0139 \\
(0.0103)\end{array}$ \\
\hline Post & $\begin{array}{l}0.0250 \\
(0.0220)\end{array}$ & $\begin{array}{l}0.0259 \\
(0.0220)\end{array}$ & $\begin{array}{l}0.192^{* * *} \\
(0.0162)\end{array}$ & $\begin{array}{l}0.0320 \\
(0.0231)\end{array}$ \\
\hline Crime & & $\begin{array}{l}-0.0166^{* *} \\
(0.00831)\end{array}$ & $\begin{array}{l}-0.0143^{*} \\
(0.00810)\end{array}$ & $\begin{array}{l}-0.0175^{*} \\
(0.00971)\end{array}$ \\
\hline GED & & $\begin{array}{l}0.00485 \\
(0.00628)\end{array}$ & $\begin{array}{l}0.00276 \\
(0.00622)\end{array}$ & $\begin{array}{l}0.00136 \\
(0.00737)\end{array}$ \\
\hline Employment Gap & & $\begin{array}{l}-0.000253 \\
(0.00560)\end{array}$ & $\begin{array}{l}0.000362 \\
(0.00561)\end{array}$ & $\begin{array}{l}0.00234 \\
(0.00607)\end{array}$ \\
\hline Constant & $\begin{array}{l}0.0769^{* * *} \\
(0.0186)\end{array}$ & $\begin{array}{l}0.108^{* * *} \\
(0.0274)\end{array}$ & $\begin{array}{l}0.000804 \\
(0.0254)\end{array}$ & $\begin{array}{l}0.0739^{* * *} \\
(0.0177)\end{array}$ \\
\hline Observations & 8239 & 8239 & 8239 & 6812 \\
\hline$R^{2}$ & 0.002 & 0.011 & 0.228 & 0.003 \\
\hline Chain FE & No & No & Yes & No \\
\hline Post $x$ Chain FE & No & No & Yes & No \\
\hline White $x$ Chain FE & No & No & Yes & No \\
\hline Center FE & Yes & Yes & Yes & Yes \\
\hline Sample & All & All & All & Quad \\
\hline
\end{tabular}

Notes: This table recreates Table 4 for NYC only. Standard errors in parenthesis clustered on chain. Dependent variable is whether the application received a callback. The Quad sample indicates the "perfect quad" sample of observations where we sent exactly 4 applications, one white/black pair in each period. Fixed effects can include, chain, post $\mathrm{x}$ chain, white $\mathrm{x}$ chain, or center, and are included as indicated. 


\section{A6. Triple Differences with GED and Emp Gap}

Table A6.1: Effects of Ban the Box on GED vs High School Diploma, Triple Differences

\begin{tabular}{|c|c|c|c|c|}
\hline & (1) & (2) & (3) & (4) \\
\hline Post $\mathrm{x}$ Treated $\mathrm{x}$ GED & $\begin{array}{l}-0.0108 \\
(0.0183)\end{array}$ & $\begin{array}{l}-0.0103 \\
(0.0192)\end{array}$ & $\begin{array}{l}-0.00360 \\
(0.0190)\end{array}$ & $\begin{array}{l}-0.0123 \\
(0.0255)\end{array}$ \\
\hline Post $x$ GED & $\begin{array}{l}0.0155 \\
(0.00971)\end{array}$ & $\begin{array}{l}0.00981 \\
(0.00962)\end{array}$ & $\begin{array}{l}0.00186 \\
(0.00969)\end{array}$ & $\begin{array}{l}0.0218^{*} \\
(0.0127)\end{array}$ \\
\hline Post $x$ Treated & $\begin{array}{l}0.0137 \\
(0.0223)\end{array}$ & $\begin{array}{l}0.0142 \\
(0.0233)\end{array}$ & & $\begin{array}{l}0.00619 \\
(0.0300)\end{array}$ \\
\hline Treated $\mathrm{x}$ GED & $\begin{array}{l}0.0186 \\
(0.0155)\end{array}$ & $\begin{array}{l}0.0203 \\
(0.0150)\end{array}$ & & $\begin{array}{l}0.0213 \\
(0.0219)\end{array}$ \\
\hline Treated & $\begin{array}{l}-0.00967 \\
(0.0278)\end{array}$ & $\begin{array}{l}-0.0114 \\
(0.0263)\end{array}$ & & $\begin{array}{l}-0.00269 \\
(0.0294)\end{array}$ \\
\hline GED & $\begin{array}{l}-0.0131 \\
(0.00868)\end{array}$ & $\begin{array}{l}-0.0124 \\
(0.00824)\end{array}$ & $\begin{array}{l}0.410^{* * *} \\
(0.131)\end{array}$ & $\begin{array}{l}-0.0189^{*} \\
(0.0110)\end{array}$ \\
\hline Post & $\begin{array}{l}0.00478 \\
(0.0132)\end{array}$ & $\begin{array}{l}0.00469 \\
(0.0137)\end{array}$ & $\begin{array}{l}0.476^{* * *} \\
(0.176)\end{array}$ & $\begin{array}{l}0.00421 \\
(0.0157)\end{array}$ \\
\hline Crime & & $\begin{array}{l}-0.0153^{* * *} \\
(0.00546)\end{array}$ & $\begin{array}{l}-0.0143^{* * *} \\
(0.00549)\end{array}$ & $\begin{array}{l}-0.0174^{* *} \\
(0.00673)\end{array}$ \\
\hline Employment Gap & & $\begin{array}{l}0.000270 \\
(0.00466)\end{array}$ & $\begin{array}{l}0.00176 \\
(0.00475)\end{array}$ & $\begin{array}{l}0.00361 \\
(0.00583)\end{array}$ \\
\hline White & & $\begin{array}{l}0.0248^{* * *} \\
(0.00572)\end{array}$ & $\begin{array}{l}0.0236^{* * *} \\
(0.00549)\end{array}$ & $\begin{array}{l}0.0243^{* * *} \\
(0.00613)\end{array}$ \\
\hline Constant & $\begin{array}{l}0.116^{* * *} \\
(0.0237) \\
\end{array}$ & $\begin{array}{l}0.115^{* * *} \\
(0.0280)\end{array}$ & $\begin{array}{l}-0.0214 \\
(0.0270) \\
\end{array}$ & $\begin{array}{l}0.107^{* * *} \\
(0.0244)\end{array}$ \\
\hline Observations & 14640 & 14640 & 14640 & 11188 \\
\hline$R^{2}$ & 0.001 & 0.027 & 0.196 & 0.003 \\
\hline Chain FE & No & No & Yes & No \\
\hline Post $x$ Chain FE & No & No & Yes & No \\
\hline GED x Chain FE & No & No & Yes & No \\
\hline Center FE & Yes & Yes & Yes & Yes \\
\hline Sample & All & All & All & Quad \\
\hline
\end{tabular}

Notes: This table recreates Table 4, substituting GED for White. Standard errors in parenthesis clustered on chain. Dependent variable is whether the application received a callback. The Quad sample indicates the "perfect quad" sample of observations where we sent exactly 4 applications, one white/black pair in each period. Fixed effects can include, chain, post $\mathrm{x}$ chain, white $\mathrm{x}$ chain, or center, and are included as indicated. 
Table A6.2: Effects of Ban the Box on Emp Gap vs No Emp Gap, Triple Differences

\begin{tabular}{|c|c|c|c|c|}
\hline & $(1)$ & $(2)$ & (3) & (4) \\
\hline Post x Treated x Emp Gap & $\begin{array}{l}-0.0248 \\
(0.0204)\end{array}$ & $\begin{array}{l}-0.0262 \\
(0.0194)\end{array}$ & $\begin{array}{l}-0.0221 \\
(0.0200)\end{array}$ & $\begin{array}{l}-0.0267 \\
(0.0231)\end{array}$ \\
\hline Post x Emp Gap & $\begin{array}{l}0.00996 \\
(0.0132)\end{array}$ & $\begin{array}{l}0.0116 \\
(0.0129)\end{array}$ & $\begin{array}{l}0.00907 \\
(0.0121)\end{array}$ & $\begin{array}{l}0.0150 \\
(0.0137)\end{array}$ \\
\hline Post $\mathrm{x}$ Treated & $\begin{array}{l}0.0205 \\
(0.0179)\end{array}$ & $\begin{array}{l}0.0220 \\
(0.0179)\end{array}$ & & $\begin{array}{l}0.0134 \\
(0.0223)\end{array}$ \\
\hline Treated x Emp Gap & $\begin{array}{l}0.0180 \\
(0.0148)\end{array}$ & $\begin{array}{l}0.0197 \\
(0.0142)\end{array}$ & & $\begin{array}{l}0.0129 \\
(0.0150)\end{array}$ \\
\hline Treated & $\begin{array}{l}-0.00920 \\
(0.0297)\end{array}$ & $\begin{array}{l}-0.0109 \\
(0.0274)\end{array}$ & & $\begin{array}{l}0.00167 \\
(0.0300)\end{array}$ \\
\hline Employment Gap & $\begin{array}{l}-0.00549 \\
(0.00969)\end{array}$ & $\begin{array}{l}-0.00775 \\
(0.00941)\end{array}$ & $\begin{array}{l}0.586^{* * *} \\
(0.103)\end{array}$ & $\begin{array}{l}-0.00377 \\
(0.00995)\end{array}$ \\
\hline Post & $\begin{array}{l}0.00756 \\
(0.0150)\end{array}$ & $\begin{array}{l}0.00383 \\
(0.0154)\end{array}$ & $\begin{array}{l}0.633^{* * *} \\
(0.154)\end{array}$ & $\begin{array}{l}0.00764 \\
(0.0171)\end{array}$ \\
\hline Crime & & $\begin{array}{l}-0.0154^{* * *} \\
(0.00541)\end{array}$ & $\begin{array}{l}-0.0150^{* * *} \\
(0.00556)\end{array}$ & $\begin{array}{l}-0.0173^{* *} \\
(0.00667)\end{array}$ \\
\hline GED & & $\begin{array}{l}-0.00247 \\
(0.00521)\end{array}$ & $\begin{array}{l}-0.00537 \\
(0.00491)\end{array}$ & $\begin{array}{l}-0.00303 \\
(0.00663)\end{array}$ \\
\hline White & & $\begin{array}{l}0.0247^{* * *} \\
(0.00569)\end{array}$ & $\begin{array}{l}0.0235^{* * *} \\
(0.00529)\end{array}$ & $\begin{array}{l}0.0243^{* * *} \\
(0.00605)\end{array}$ \\
\hline Constant & $\begin{array}{l}0.112^{* * *} \\
(0.0233)\end{array}$ & $\begin{array}{l}0.113^{* * *} \\
(0.0277)\end{array}$ & $\begin{array}{l}-0.0133 \\
(0.0251)\end{array}$ & $\begin{array}{l}0.102^{* * *} \\
(0.0231)\end{array}$ \\
\hline Observations & 14640 & 14640 & 14640 & 11188 \\
\hline$R^{2}$ & 0.001 & 0.026 & 0.194 & 0.003 \\
\hline Chain FE & No & No & Yes & No \\
\hline Post x Chain FE & No & No & Yes & No \\
\hline Emp Gap x Chain FE & No & No & Yes & No \\
\hline Center FE & Yes & Yes & Yes & Yes \\
\hline Sample & All & All & All & Quad \\
\hline
\end{tabular}

Notes: This table recreates Table 4, substituting Emp Gap for White. Standard errors in parenthesis clustered on chain. Dependent variable is whether the application received a callback. The Quad sample indicates the "perfect quad" sample of observations where we sent exactly 4 applications, one white/black pair in each period. Fixed effects can include, chain, post $\mathrm{x}$ chain, white $\mathrm{x}$ chain, or center, and are included as indicated. 